
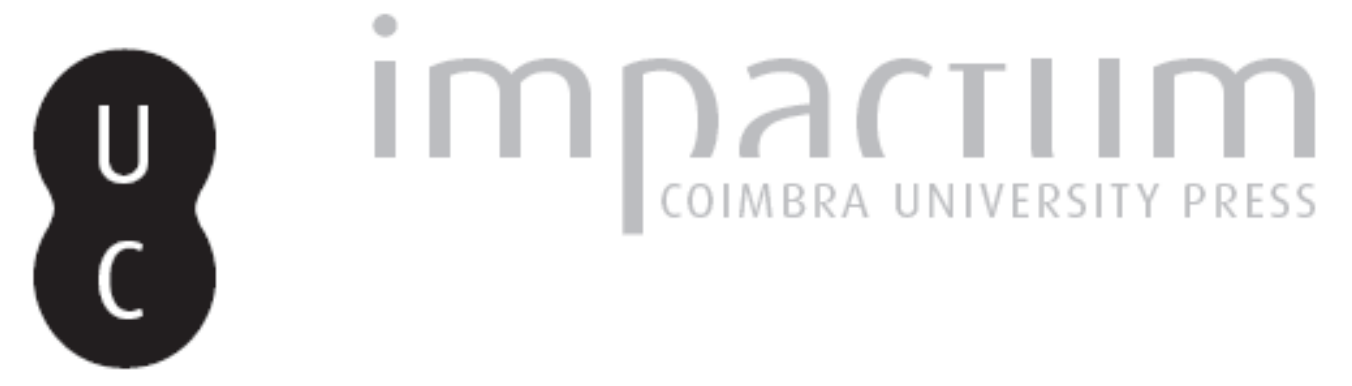

\title{
As vias romanas de Olisipo a Augusta Emerita
}

Autor(es): $\quad$ Alarcão, Jorge de

Publicado por: Faculdade de Letras da Universidade de Coimbra

URL persistente:

URI:http://hdl.handle.net/10316.2/37730

DOI:

DOI:http://dx.doi.org/10.14195/1647-8657_45_13

Accessed : $\quad$ 26-Apr-2023 05:43:42

A navegação consulta e descarregamento dos títulos inseridos nas Bibliotecas Digitais UC Digitalis, UC Pombalina e UC Impactum, pressupõem a aceitação plena e sem reservas dos Termos e Condições de Uso destas Bibliotecas Digitais, disponíveis em https://digitalis.uc.pt/pt-pt/termos.

Conforme exposto nos referidos Termos e Condições de Uso, o descarregamento de títulos de acesso restrito requer uma licença válida de autorização devendo o utilizador aceder ao(s) documento(s) a partir de um endereço de IP da instituição detentora da supramencionada licença.

Ao utilizador é apenas permitido o descarregamento para uso pessoal, pelo que o emprego do(s) título(s) descarregado(s) para outro fim, designadamente comercial, carece de autorização do respetivo autor ou editor da obra.

Na medida em que todas as obras da UC Digitalis se encontram protegidas pelo Código do Direito de Autor e Direitos Conexos e demais legislação aplicável, toda a cópia, parcial ou total, deste documento, nos casos em que é legalmente admitida, deverá conter ou fazer-se acompanhar por este aviso.

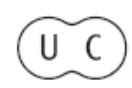




\section{CONIMBRIGA}

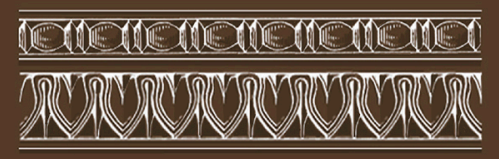

INSTITUTO DE ARQUEOLOGIA

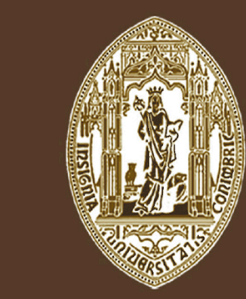

VOLUME XLV - 2006

FACULDADE DE LETRAS UNIVERSIDADE DE COIMBRA 
JoRGE DE ALARCÃo

Professor catedrático aposentado da Faculdade de Letras de Coimbra

AS VIAS ROMANAS DE OLISIPO A AUGUSTA EMERITA

"Conimbriga" XLV (2006) p. 211-251

Resumo: Três estradas ligavam Olisipo (Lisboa) a Augusta Emerita: uma, por Salacia (Alcácer do Sal) e Ebora (Évora); outra, por Aritium Praetorium e Abelterium (Alter do Chão); a terceira, por Tubucci.

A maior parte das localidades mencionadas pelo Itinerário de Antonino ao longo destas vias ainda não foi identificada e os exactos percursos continuam a suscitar dúvidas.

O presente artigo pretende fazer um balanço crítico da investigação até agora realizada por vários autores e apresenta algumas hipóteses que, todavia, carecem de confirmação no terreno.

Summary: Three Roman roads linked Olisipo (Lisboa) and Augusta Emerita: one by Salacia (Alcácer do Sal) and Ebora (Évora); a second by Aritium Praetorium and Abelterium (Alter do Chão); and a third by Tubucci. Most of the localities referred to in Antonine's Itinerary have yet to be identified and their exact positions remain in doubt.

This article intends to present a critical appraisal of research carried out since the $16^{\text {th }}$ century by various authors and puts forward some suggestions that need to be confirmed by field-walking. 
(Página deixada propositadamente em branco) 


\section{AS VIAS ROMANAS DE OLISIPO A AUGUSTA EMERITA}

O Itinerário de Antonino menciona três vias entre Olisipo e Augusta Emerita: uma, por Salacia e Ebora; outra, por Aritium Praetorium e Abelterium; a terceira, por Tubucci.

Apesar de muitos estudos já feitos e publicados sobre estas estradas (uns mais abrangentes, outros mais localizados em certos troços), permanecem dúvidas na reconstituição dos traçados e ignorâncias quanto à localização da maior parte das estações que o Itinerário de Antonino menciona. Das 20 paragens que aquele roteiro refere no conjunto das três vias (excluímos os pontos de partida e de chegada, Olisipo e Augusta Emerita), apenas 3 se podem considerar seguramente identificadas: Scallabis (Santarém), Salacia (Alcácer do Sal) e Ebora (Évora). Três outras acham-se localizadas com a maior das probabilidades, ainda que faltem provas inequívocas da sua posição: Ierabriga, entre Paredes e Quinta do Bravo (nas imediações de Alenquer), Caetobriga, em Setúbal e Budua, já em Espanha. As restantes 14 continuam a suscitar dúvidas.

A raridade dos miliários com indicação das milhas, as incertezas quanto às suas posições originárias exactas e as divergências dos diversos manuscritos do Itinerário de Antonino quanto às distâncias entre certas estações viárias dificultam a reconstituição dos percursos e a identificação dos lugares por onde as vias corriam.

Não temos a pretensão de resolver satisfatoriamente os problemas ou de propor traçados indisputáveis, mas apenas a de fazer o balanço do que se sabe e do que ainda se ignora. $O$ percurso das estradas tem sido por muitos autores procurado sem ter sido ainda achado em toda a sua extensão e o nosso artigo é apenas mais uma procura. 


\section{A Via por Salacia e Ebora}

O Itinerário de Antonino indica as seguintes paragens e distâncias:

$\begin{array}{lll}\text { Iter ab Olisipone Emeritam } & \text { CLXI } & \text { CXLI, CLXXVII } \\ \text { Equabona } & \text { XII } & \text { XVI } \\ \text { Caetobriga } & \text { XII } & \\ \text { Caeciliana } & \text { VIII } & \text { XII } \\ \text { Malateca } & \text { XXVI } & \text { XVI } \\ \text { Salacia } & \text { XII } & \\ \text { Ebora } & \text { XLIIII } & \\ \text { Ad Adrum flumen } & \text { VIIII } & \\ \text { Dipone } & \text { XII } & \\ \text { Evandriana } & \text { XVII } & \\ \text { Emerita } & \text { VIIII } & \end{array}$

Não sabemos, ao certo, onde se faria o desembarque de quem atravessava o Tejo, de Olisipo para a margem esquerda do rio. Talvez em Almada ou no Seixal - ou no fundo de um dos esteiros do Tejo. Mário Saa (1967: 17-18) admitiu ainda Cacilhas ou Porto Brandão. A dúvida repercute-se de imediato na localização de Equabona, que ficava a XII ou XVI milhas do ponto onde se iniciava a viagem por terra.

A identificação de Equabona com Coina (FERREIRA, 1959: 175-176) não é segura e suscita muitas dúvidas.

Se o nome "Coina" pode ter derivado de Equabona (VASCONCELOS, 1905: 21), não é forçoso identificar a actual povoação de Coina com a Equabona romana, pois pode ter havido migração do topónimo.

A hipótese de a viagem, pelo rio, se fazer entre Lisboa e Coina não é de rejeitar, dada a posição de Coina no fundo de um dos esteiros do Tejo. Nesse caso, a distância de XII milhas corresponderia à travessia do rio e o Itinerário de Antonino teria convertido em milhas a distância de um trajecto fluvial que normalmente se calculava em estádios. Mas, se localizássemos Equabona em Coina, a distância daquela estação viá-

* Nesta coluna indicamos as distâncias adoptadas por RoLdÁn HERVÁs em Itineraria Hispana.

** Nesta outra coluna referimos as distâncias alternativas que se encontram em alguns manuscritos do Itinerário de Antonino. 
ria a Caetobriga seria muito superior às XII milhas do roteiro (assumindo a identificação de Caetobriga com Setúbal).

Se o desembarque se fizesse no fundo do esteiro onde hoje fica Coina, talvez Equabona se situasse entre S. Lourenço e Vendas de Azeitão. A estrada iria depois, por Palmela, a Setúbal.

As dúvidas que durante muito tempo subsistiram quanto à identificação de Caetobriga parecem resolvidas: os achados pré-romanos e romanos de Setúbal são hoje suficientemente abundantes e significativos para podermos equacionar Caetobriga com Setúbal (SILvA e SoARES, 1986: 178-194; SOARES, 2000).

Dando por boa esta identificação, devíamos procurar Caeciliana a 12 ou 18 quilómetros a nordeste de Setúbal.

O nome Caeciliana pode corresponder a mansio ou mutatio dependente da villa de uma família Caecilia, embora este gentilício não seja conhecido na área de Setúbal ou Alcácer do Sal. Numa outra hipótese, a estação teria derivado seu nome do de um acampamento de Quinto Cecílio Metelo Pio (Tovar, 1976: 216), em cujo lugar, uma vez despedidas as tropas, se teria instalado a estação de muda ou mesmo algum aglomerado urbano secundário.

O possível acampamento de Q. Cecílio Metelo Pio no lugar que depois viria a ser a Caeciliana do Itinerário de Antonino alojaria uma legião? E seria um acampamento fortificado com algum muro de terra e fosso? Parece difícil admitir que o fosse - pois, nesse caso, vestígios dele já teriam sido identificados por algum dos muitos investigadores que têm trabalhado na área de Setúbal e da Arrábida.

Não é de rejeitar a hipótese de Q. Cecílio Metelo Pio ter estacionado aqui com algumas tropas (quantas e quais?) sem ter fortificado o lugar por não pensar fazer dele base duradora de operações. Ou, por essa razão, poderia tê-lo defendido de modo tão precário que os vestígios do acampamento teriam desaparecido ou não seriam hoje facilmente reconhecíveis. Mas a memória do estacionamento do general romano teria persistido e dado origem ao nome Caeciliana.

Seja como for, e assumindo a identificação de Caetobriga com Setúbal, Caeciliana deveria achar-se nas imediações de Águas de Moura.

Também não sabemos situar Malateca, se bem que desse nome derive o actual de uma vila e de uma ribeira, Marateca. Atentas as distâncias do Itinerário de Antonino, não é possível situar Malateca na vila de Marateca. 
Talvez a estrada, a partir de Águas de Moura, continuasse ao longo da ribeira de Marateca e algures, entre Landeira e Cabrela, inflectisse para sul ou sudeste. Parecem abundantes os vestígios romanos entre estas duas povoações (SAA, 1963: 25). Um caminho de Setúbal por Águas de Moura, Landeira e serra do Loureiro até Alcácer do Sal totalizaria cerca de 36 quilómetros - distância todavia inferior às contagens do Itinerário de Antonino. Um percurso pelas imediações de Cabrela e por Casebres corresponde a cerca de 42 quilómetros - e articular-se-ia com a distância de XII + XVI milhas.

As dúvidas sobre as correctas distâncias entre Caetobriga e Caeciliana e entre esta e Malateca (dadas as divergências dos diversos manuscritos do Itinerário de Antonino) tornam incerto um percurso que vários autores têm tentado reconstituir sem que haja uma proposta inteiramente convincente (FERREIRA, 1959; SAA, 1956; ARIAS, 1987: 301-303; Alarcão, 2004 (1): 320-321).

A partir da Salacia (Alcácer do Sal) e até Ebora (Évora) são menores as dúvidas.

De Alcácer do Sal, a estrada viria por Porto da Lama, Monte dos Carvalhos de Baixo, Santa Susana e Portagem.

Em Porto da Lama (Alcácer do Sal) havia um miliário dedicado a Diocleciano, Maximiano, Constâncio Cloro e Galério (IRCP n. ${ }^{\circ} 671$, com localização correcta na p. 758 , nota 1 ).

No Monte dos Carvalhos de Baixo parece encontrar-se um miliário anepígrafo (FERREIRA et alii, 1993: 81).

André de Resende (1996: 175) publicou um miliário de Caracala que viu "entre Alcácer do Sal e Évora, na colina sobranceira ao pequeno rio que tem o nome de Mourinho". O rio Mourinho corre por Santa Susana (FERREIRA et alii, 1993: 40). Hübner deu este miliário como falso em CIL II 434*, mas não vemos razões sérias para duvidar dele.

Em Portagem, uma área considerável de vestígios permite supor estação romana de alguma importância, se bem que o que dela se acha noticiado (FERREIRA et alii, 1993: 91) nos deixe dúvidas sobre se se trata de villa, mansio ou mesmo vicus.

A estrada passaria ainda pela herdade da Biscainha, onde há vestígios de calçada romana (FERREIRA et alii, 1993: 69).

Vestígios de uma antiga estrada no Monte dos Andrades (freguesia de S. Brissos, concelho de Montemor-o-Novo) e fragmentos de dois supostos miliários anepígrafos no mesmo monte e no da Venda (este, a pouco mais de dois quilómetros a ocidente do primeiro (BILOU, 2000: 
9-10; BILOU, 2005: 38-40; SAA, 1956: 109-110) permitem admitir que a via romana passava por estes lugares. É certo que a estrada da qual se conservam vestígios não é inequivocamente romana e que só supostamente as colunas observadas correspondem a miliários anepígrafos. O traçado, porém, é credível, ainda que possam suscitar-se algumas dúvidas quanto à sua harmonização com os dois miliários que André de Resende (1996: 175) refere entre Alcácer do Sal e Évora, numa propriedade a que chamam - diz o autor - Tabuleiros. Um deles era já ilegível no tempo do humanista. O outro seria consagrado a Maximiano e assinalaria a milha XII contada a partir de Ebora.

Hübner publicou este miliário como falso em CIL II 433*: damnando omnimo tam propter nomenclaturem insolentem quam propter Eborae mentionem. Se a nomenclatura imperial é, de facto, suspeita, o certo é que o topónimo Tabuleiros e o monte dos Tabuleiros de Baixo se acham a cerca de 18 quilómetros (isto é, XII milhas) de Évora, para ocidente. Quanto à nomenclatura imperial, talvez algumas letras já não fossem visíveis no tempo de André de Resende ou o humanista, na sua deslocação, não tenha copiado o texto no local e depois o tenha reconstituído de memória e de forma incompleta ou errónea. Devemos pensar que, no séc. XVI, não havia a preocupação de rigor que hoje temos na transcrição das epígrafes. No caso de miliários de granito, com letras por vezes difíceis de reconhecer ou mesmo já apagadas, os autores podiam tomar, in loco, algumas notas e depois, nos seus escritórios, reconstituiriam os textos sem se preocuparem com distinguir letras vistas, de letras reconstituídas. Na reconstituição cometeriam alguns erros, até porque não dispunham, como nós, de corpora onde hoje podemos facilmente encontrar paralelos que ajudam na reconstituição e até na própria leitura.

Mário Saa (1967: 27) declara ter visto junto do "monte" de Tabuleiros de Baixo, "uma coluna legionária, ainda erecta, mas em vias de ser dali retirada para qualquer destino utilitário".

A rejeição do miliário de Tabuleiros como falso poderá relevar de hipercriticismo. Se o reabilitarmos, não só teremos uma pista para o traçado da estrada como uma informação importante quanto à extensão do território da civitas de Ebora, que, a ocidente, viria pelo menos até Tabuleiros. Mas o limite entre as civitates de Ebora e Salacia passava, talvez,um pouco mais a ocidente.

A cerca de 6 quilómetros a ocidente de Tabuleiros, o topónimo Padrão poderá derivar de algum miliário que aí existisse (ainda que se possam imaginar outras explicações para o nome). 
Mário Saa (1956: 114) regista outros miliários anepígrafos em Valverde e entre esta localidade e Monte da Mitra. Bilou (2005: 40-41), admitindo o percurso por Valverde, faz seguir a estrada romana pelas proximidades do moinho da Esparragosa, onde localizou um fragmento de miliário anepígrafo.

Qualquer que tenha sido o exacto traçado da via romana nesta área, a orientação global parece-nos definida e o cômputo das XLIV milhas de Salacia a Ebora afigura-se-nos correcto. Mas merece atenção a proposta de Bilou (2005: 45-51) de uma via alternativa que passaria pelo convento de Nossa Senhora da Esperança e pela herdade do Barrocal, ribeira da Viscosa, quinta do Pomarinho e albufeira do Monte das Flores. É neste percurso que integra a passagem por Tabuleiros de Baixo. Junto à albufeira do Monte das Flores identificou um fragmento de miliário epigrafado, onde julgou poder ler-se o nome do imperador Décio. A leitura suscita muitas dúvidas.

Para Mário Saa (1956: 127, 137-140), as três paragens que o Itinerário de Antonino indica a seguir a Ebora, isto é, ad Adrum flumen, Dipone e Evandriana, corresponderiam a Bencatel ou Pardais, Juromenha e Badajoz. A proposta afigura-se-nos inaceitável, pois de Évora a Bencatel vão mais de 42 quilómetros em linha recta, muito mais que as VIIII milhas que o Itinerário de Antonino regista entre Ebora e ad Adrum flumen.

É óbvio que o roteiro omitiu estações entre Ebora e Augusta Emerita. Sobre isso há consenso, visto que, mesmo em linha recta, a distância entre as duas cidades excede largamente as XLVII milhas do roteiro. O problema reside em saber se ad Adrum flumen, Dipo e Evandriana eram as três paragens que se seguiam a Ebora (localizadas, portanto, em território actualmente português) ou as três últimas que o viajante faria imediatamente antes de chegar à capital da Lusitânia (neste caso, localizadas em território hoje espanhol).

Situando o problema nesta alternativa, implicitamente admitimos que as estações omissas ficavam entre Evandriana e Augusta Emerita ou, pelo contrário, entre Ebora e ad Adrum flumen. Poderíamos, porém, considerar outras hipóteses, como, por exemplo, que ad Adrum flumen ficasse a VIIII milhas de Évora e Dipo a XXVI milhas de Augusta Emerita. Em tal caso, as estações omissas situar-se-iam entre ad Adrum flumen e Dipo.

J.-G. Gorges e F. G. Rodríguez Martín (1999), tendo reconstituído o percurso de uma via romana pela margem esquerda do Guadiana, 
identificaram Evandriana com Las Torrecillas, na área de Arroyo de San Serván - ao quilómetro 355 da auto-estrada Madrid-Badajoz -, Dipo com Talavera la Real e o Adrum flumen com o rio Xévora.

Pelo contrário, nós mesmos propusemos a ribeira do Freixo como Adrum flumen, situámos Dipo em Évora Monte e sugerimos a localização de Evandriana em Silveirona ou nas imediações de Bencatel (AlARCÃo, 1999 e 2001).

Se a Dipo do Itinerário de Antonino é a mesma de Salústio 1.113 (em SCHUlten, 1937: 175), parece-nos credível a sua identificação com Évora Monte. Diz Salústio que era valida urbs. O adjectivo ajustase à posição de Évora Monte. Pelo contrário, junto de Talavera la Real não encontramos lugar que possa considerar-se valida urbs. Temos de reconhecer, porém, que não é segura a identificação da Dipo de Salústio com a Dipo do Itinerário de Antonino, pois o topónimo podia repetir-se.

Seja como for, a estrada de Évora para Mérida passaria por Évora Monte, pois aí se encontrou um miliário de Flávio Júlio Valério Licínio Júnior e Flávio Cláudio Constantino, atribuível a 320 d. C. (IRCP, n. ${ }^{\circ}$ 674). Bilou traçou recentemente com algum pormenor o percurso entre Évora e Évora Monte (BILOU, 2005: 53-57).

Em trabalhos anteriores (ALARCÃo, 1999 e 2001) propusemos a localização de Evandriana em Silveirona ou na área de Bencatel. De Evandriana, a via romana iria a Montobriga, estação que o Itinerário de Antonino menciona na via por Tubucci e que identificámos com Monte da Nora. Assim, o percurso de Evandriana a Mérida seria o seguinte:

Evandriana
Montobriga
Ad Septem Aras
Plagiaria
Emerita

Omitindo as estações de Montobriga, ad Septem Aras e Plagiaria, o roteiro teria atribuído, ao percurso de Evandriana a Mérida, a distância que, na realidade, era a de Evandriana a Montobriga.

A nossa hipótese ganharia credibilidade se, no Itinerário de Antonino, a via por Salacia e Ebora viesse depois da via por Tubucci. Em tal caso, as estações de Montobriga, ad Septem Aras e Plagiaria teriam
VIIII

XIIII

$\mathrm{XX}$

$\mathrm{XXX}$ 
sido omitidas porque figuravam numa via já referenciada. Mas, ainda admitindo tal hipótese, o Itinerário de Antonino deveria ter compendiado as distâncias desta forma:

Evandriana
Montobriga

Emerita
VIIII

LXIIII

Na edição de Wesseling (a que serve de base a todos os arqueólogos, directa ou indirectamente), a via por Salacia e Ebora vem antes e não depois da de Tubucci. Parece difícil, pois, admitir uma omissão por repetição de estações viárias já anteriormente citadas - a menos que, no original do roteiro, a ordem das vias não fosse a que Wesseling publicou.

Sem excluirmos a hipótese de a via de Ebora a Augusta Emerita vir entroncar na de Olisipo a Augusta Emerita por Tubucci, mas acrescentando uma hipótese às outras já por nós apresentadas, podemos pensar que, de Évora Monte, a estrada vinha a Estremoz e daqui seguia a Borba, em cujas imediações ficaria a estação de Evandriana. Adiante, porém, consideraremos a possibilidade de a via por Ebora e a via por Tubucci, encontrando-se em Estremoz, terem percursos diferentes, indo a primeira por Elvas e Badajoz e a segunda, por Degolados e Campo Maior. Voltaremos também ao problema da localização de Montobriga.

É infelizmente desconhecido o lugar de proveniência de um miliário que se encontra no museu de Vila Viçosa (IRCP, n. ${ }^{\circ}$ 676) e que, não obstante não conter indicação de milhas, poderia ajudar-nos a reconstituir o percurso da via se soubéssemos onde é que foi encontrado.

\section{A Via de Olisipo a Augusta Emerita por Aritium Praetorium e Abelterium}

O Itinerário de Antonino regista, nesta estrada, as seguintes paragens e distâncias:

Alio itinere ab Olisipone

Emeritam

Aritio Praetorium

Abelterio

Matusaro
CLIIII

XXXVIII

XXVIII

XXIIII
CXLIIIII,

CXLVIII 


$\begin{array}{lll}\text { Ad Septem Aras } & \text { LX [... } & \text { VIII } \\ \text { Budua } & \text { XII } & \\ \text { Plagiaria } & \text { VIII } & \text { XII } \\ \text { Emerita } & \text { XXX } & \end{array}$

É consensual que a primeira das paragens indicadas (a de Aritium Praetorium) não ficaria a XXXVIII milhas de Olisipo mas a essa distância do ponto onde se cruzaria o Tejo. Eventualmente, ficaria a XXVIII ou XXX - pois essas distâncias também se encontram em manuscritos de Itinerário de Antonino. O viajante, saído de Olisipo, passaria por Ierabriga e Scallabis (estações mencionadas pelo Itinerário de Antonino na via de Olisipo a Bracara Augusta), cruzaria o Tejo em Scallabis, e Aritium Praetorium achar-se-ia a XXXVIII milhas desta cidade (PEREIRA, 1937: 51).

Mário Saa (1967: 11) admitiu que a travessia do Tejo se fazia em Muge e que as milhas até Aritium Praetorium se contavam desse ponto. Por outro lado, Vasco Mantas (1996: 769-770 e 2004: 440) sustentou que a travessia do rio, para os viajantes que tomavam esta estrada, se faria no vau de Escaroupim. Sem discutirmos a existência desse vau, duvidamos que esse fosse o ponto de partida para a contagem das milhas até Aritium Praetorium. Que vantagem haveria, para quem seguisse para este lugar (ou para Aritium Vetus), em fazer a travessia do Tejo em Escaroupim? Não seria mais conveniente fazê-la em Scallabis? E teria o Itinerário de Antonino indicado um percurso que só seria eventualmente praticável no Verão? Ou haveria ponte de barcas em Escaroupim?

Admitindo uma travessia do Tejo em Escaroupim, esta encurtaria a viagem pela via de Tubucci - da qual adiante trataremos. Mas, pelo que respeita à via de Aritium Praetorium e Abelterium, vamos assumir, como hipótese, que a travessia do Tejo se fazia em Santarém.

A estrada passaria por Terrugem (onde haveria uma ponte, vid. MANTAS, 1996: 773-775) e por Alpiarça, em cujo termo (mas onde, exactamente?) havia dois miliários dedicados a Tácito e datáveis de finais de 275 d. C. (CIL II 4635 e 4636 = IRCP, n.os 665 e 666). José d'Encarnação (1984: 726-727) sugeriu que o miliário CIL II 4630 (= IRCP, n. ${ }^{\circ} 667$ ), a que Hübner atribuiu procedência incerta (perto de Évora ou Beja?), se acharia também no termo de Alpiarça. Não vemos, porém, suficiente fundamento para essa hipótese, ainda que ela não deva ser excluída. 
A estrada avançaria por Junceira (Vale de Cavalos, Chamusca), onde se recolheu uma inscrição na qual não se lê mais que Bono Rei[p(ublicae)] (IRCP, n. ${ }^{\circ}$ 642).

A fórmula Bono Reipublicae nato é comum em inscrições honorificas do séc. IV d. C.. Mas a inscrição de Junceira não se reduziria à formula Bono Reipublicae? Nesse caso, não assinalaria uma mutatio, isto é, um serviço público para utilidade e benefício dos cidadãos? A 11 ou 12 milhas da travessia do Tejo, a paragem seria necessária. José d'Encarnação, a partir da fotografia do monumento (cujo paradeiro infelizmente se ignora), admite tratar-se de ara. Quer nesse caso, quer no de pedestal de estátua, o mais provável é que estivesse em lugar público - neste caso, em estação de muda. Será que aras, com inscrição Bono Reipublicae, substituíram, no Baixo Império, os anteriores altares consagrados aos Lares Viales?

A estrada acompanharia a ribeira de Alpiarça (também chamada de Ulme), ao longo da qual haveria diversos miliários, segundo informação de André de Resende (1996: 78-179): a Maximino e Máximo (?), a Trajano (CIL II 439*) e a Tácito (CIL II 4635 e $4636=$ IRCP, n. ${ }^{\text {os }} 665$ e 666) - além de outros nos quais, por fragmentados, já se não lia o nome dos imperadores (entre eles, CIL II 4637 e 4634).

O miliário que Resende atribui a Caio Júlio Vero [...] seria, na realidade, dedicado a Maximino e Máximo. Talvez o texto, no séc. XVI, já não fosse visível senão em partes e André de Resende se não tenha aplicado muito na leitura e tenha dado dele uma versão abreviada. Se a versão de Resende é inaceitável, talvez se não deva rejeitar este miliário, tanto mais que, adiante, nas Mestas, o humanista viu um outro consagrado ao imperador Caio Júlio Vero Maximino e ao César Caio Júlio Vero Máximo.

Infelizmente, André de Resende não recordou a posição exacta dos miliários. Diz o humanista que "o caminho, a partir de Santarém, sobranceiro ao ópido de Alpiarça, era conduzido através das nascentes do rio Alpiarça": Não se deve entender, porém, que os miliários estavam todos junto às nascentes do rio: estariam antes em várias posições, ao longo dele, a intervalos de mil passos (como diz Resende).

O miliário de Trajano, segundo o humanista, indicaria XI milhas. O desenho publicado por Resende deixa-nos dúvidas sobre a leitura X ou XI. Talvez o traço vertical fosse um simples risco ou ranhura que Resende terá tomado por I. Estaria o miliário perto da suposta mutatio ou mansio de Junceira? Se a ordem por que os miliários se achavam era 
a que Resende indica, o que supomos dedicado a Maximino e Máximo estaria a jusante e os de Tácito, a montante.

Em Pocariça, Mário Saa (1956: 243-244) recolheu um miliário consagrado a Flávio Valério Constantino - miliário do qual José d'Encarnação (1995: 642-643) deu correcta leitura.

De Pocariça, a estrada ia, segundo Mário Saa (1956: 247), a Semideiro.

Entre os casais de Vale de Lama e Aranhas de Baixo foi encontrado um miliário dedicado a Constantino (Silva, 1989 e Silva, BATISTA e Gaspar, 2003). Joaquim Candeias Silva supõe que foi levado de Tamazim, onde originalmente se encontraria. Parece-nos credível, porém, que o miliário estivesse in situ ou apenas ligeiramente deslocado da sua posição original. Mas a estrada passaria realmente por Tamazim, onde Mário Saa (1956: 253) viu dois miliários anepígrafos.

A estrada, segundo Mário Saa (1956: 257 e 264) iria depois a Rapazes (Bemposta, Abrantes) e passaria pelas imediações do marco geodésico de Vale do Zebro.

Não podemos deixar de referir aqui a informação de André de Resende (1996: 179) de que, "junto à encruzilhada a que chamam Mestas, estão quatro colunas caídas". Segundo o humanista, três teriam "inscrições inutilizadas". Mas André de Resende dá o texto que leu no quarto miliário, consagrado a Caio Júlio Vero Maximino e Caio Júlio Vero Máximo. Hübner publicou o texto como falso em CIL 441*. José d'Encarnação identificou este miliário com um outro, que considera autêntico, encontrado na herdade da Torre do Curvo (Santo Aleixo, Monforte) (IRCP, n. ${ }^{\circ}$ 664). É provável que se trate de dois miliários diferentes, ainda que ambos consagrados a Maximino e Máximo. Segundo o desenho de Resende, no final do texto haveria a indicação IIII, ainda que sem MP.

A posição exacta desta encruzilhada das Mestas suscita algumas dúvidas, Mário Saa (1956: 254 e 259) dá as coordenadas de Lat. 39 17' 52" e Long. $0^{\circ} 45^{\prime} 47^{\prime \prime}$ a leste de Lisboa e identifica o lugar com o de uma antiga estalagem chamada Poiso. Costa Veiga (1941: 21-22) parece considerar que havia dois lugares com o mesmo nome de Mestas: um, a oeste de Montargil e a norte de Couço; outro, sobre a ribeira de Erra, entre Lamarosa e Montargil.

Por esta área no séc. XVI despovoada passou então Claude de Bronseval, que escreveu: per desertam regionem cum immoderatissimo 
imbre usque ad mediam diem venimus semper incedentes usque ad unicam domum in deserto vocatam As Mester (BRONSEVAL, 1970: I, 317; MANTAS, 1996: 516).

A palavra "mestas"está relacionada com a transumância mas, segundo A. de Almeida Fernandes (1999: 423), também significaria “confluências".

A estrada que vimos seguindo desde as imediações de Alpiarça continuava por Água Branca (Bemposta, Abrantes), onde os vestígios romanos são abundantes (SAA, 1956: 265; LiZARdo, 2003; SilvA, Batista e Gaspar, n. p.). Perto de Água Branca existem também os topónimos Vale da Estrada e Monte do Padrão.

Corresponderá Água Branca a Aritium Praetorium? Mário Saa hesitou entre a localização desta mansio em Abrantes ou Água Branca (SAA, 1956: 150 e 1967: 12). Pelo percurso que vimos seguindo, a distância de Água Branca a Santarém é de cerca de 55 quilómetros, correspondendo, mais ou menos, às XXXVIII milhas do Itinerário de Antonino entre Scallabis e Aritium Praetorium. O lugar de Água Branca não fica longe dos marcos geodésicos de Bufão e Água Branca, entre os quais Costa Veiga (1941: 33) supôs que deveria situar-se Aritium Praetorium.

O nome praetorium sugere um acampamento militar romano, e mesmo um acampamento ocupado por legião. O lugar poderia ter sido abandonado pelas tropas sem que se tivesse perdido memória dessa ocupação - e no mesmo sítio teria sido instalada uma mansio que teria conservado o nome. Eventualmente, mais do que simples mansio, o lugar poderia ser um vicus. Mário Saa (1956: 265) refere-se ao achado de "inumerável quantidade de moedas romanas, anteriores ao Império" quando, em 1944, se abriu um poço.

O nome de Aritium Praetorium deve relacionar-se com o de Aritium Vetus. Ficava esta cidade, que talvez tenha sido capital de civitas, nas imediações de Alvega (AlARCÃo, 2004 (2): 194-197). Não podemos deixar de perguntar-nos se Aritium Praetorium não ficaria integrada na civitas de Aritium Vetus.

Se reabilitarmos o miliário registado por André de Resende nas Mestas, e se este assinalava IIII milhas, Água Branca seria caput viarum. Ora a contagem das milhas fazia-se normalmente a partir de uma capital de civitas. Será que Aritium Praetorium era, afinal, capital de civitas e Aritium Vetus, um aglomerado urbano dependente? 
O nome Praetorium não parece muito adequado a capital de $\mathrm{ci}$ vitas. É certo que, na Cisalpina, Aosta se chamou Augusta Praetoria. Mas o nome, neste caso, justificou-se por ter Augusto estabelecido, como colonos, legionários veteranos. Não terá sido o caso de Aritium Praetorium.

Por outro lado, nem sempre se tomava, como caput viarum, uma capital de civitas. Assim, devemos manter alguma reserva sobre o estatuto de Aritium Praetorium. Mas Água Branca é certamente um sítio a merecer intervenção arqueológica prioritária.

Não podemos deixar de surpreender-nos pela ausência de qualquer referência às ruínas de Água Branca em André de Resende. Se o humanista passou pelas Mestas, não terá ao menos ouvido falar de um sítio que distaria pouco mais de uma légua? Talvez não houvesse, nessa data, muitos vestígios visíveis - nem memória do sítio como lugar importante na época romana. Por outro lado, talvez André de Resende, a partir de Mestas, tenha tomado o caminho de Constância e Abrantes, sem passar por Água Branca.

De Água Branca, a estrada continuaria pelas imediações do marco geodésico de Bufão (SAA, 1956: 266-267) e iria a Ponte de Sor. Aqui descobriu-se parte de uma inscrição monumental de Trajano, em placa marmórea que teria cerca de $4,5 \mathrm{~m}$ de comprido por $0,80 \mathrm{~m}$ de altura (Silva e EnCARNAÇão, 1990). O nome do imperador em nominativo, [TRA]IANVS, exclui uma homenagem ao optimus princeps e obriga a considerar que a inscrição recordaria obra feita pelo imperador. Terá sido uma ponte, sobre a qual haveria um arco? Terminaria a inscrição por algo como pontem lapideum fecit? A dimensão do rio não justificava obra de grande escala, mas o lugar poderia ser importante como extrema oriental do conventus Scallabitanus.

Da estrada que vimos seguindo havia, provavelmente, uma ligação a Aritium Vetus (nas imediações de Alvega). A ligação, todavia, não está identificada. J. Candeias da Silva publicará brevemente em Ficheiro Epigráfico um novo miliário de Constantino achado em Crucifixo (Bemposta, Abrantes), perto das ruínas das termas romanas de Santa Margarida da Coutada. Este achado repõe o problema da interpretação deste edifício. Não se tratará de balneum de uma mansio? Talvez por Crucifixo passasse uma estrada que, de Alvega, se dirigisse a Selium (Tomar) e não propriamente uma via que fizesse a ligação de Alvega a Aritium Praetorium. 
A partir de Ponte de Sor, o percurso da estrada pode seguir-se graças a vários miliários, muitos deles, todavia, anepígrafos e outros reduzidos a fragmentos: Ponte de Sor, Cabeceiros, Coutadas e Torre das Vargens (freguesia de Ponte de Sor), Nossa Senhora dos Prazeres, Fonte da Cruz, Freixial, herdade de Vale da Estrada e S. Marcos (na freguesia de Vale de Açor), monte da Coreia, Vale de Perlim, Rascão (Chancelaria), Vale do Gato e monte da Celada (Seda) (PEREIRA, 1912: 218-220; Pereira, 1937: 58; SAA, 1956: 278 s.; AlarCão, 1988, estações 6/88 a 6/100 e 6/120; SiLVA, 1988).

Infelizmente, quase todos estes miliários são anepígrafos. Exceptuamos os de Ponte de Sor, consagrado a Probo (IRCP, n. ${ }^{\circ}$ 668), um de Fonte da Cruz consagrado a Caracala (?) e o de Nossa Senhora dos Prazeres, dedicado a Tácito (IRCP, n. ${ }^{\circ}$ 666a; ENCARNAÇÃo, 1995: 639-641). No fragmento de Coutadas apenas se lê: CONSTA[...]; no de Freixial, BONO R P; no de Fonte da Cruz, IMP CAE [...][...]; no de Torre das Vargens, [...]AV[...]CO[...] (SilvA, 1988).

Carece-se de um estudo pormenorizado deste troço de via entre Ponte de Sor e a ribeira de Seda, com confirmação dos miliários e identificação correcta dos lugares de achado. É curiosa a abundância de marcos, contrastante com a sua raridade a ocidente de Ponte de Sor. Aqui poderia passar-se da civitas de Aritium Praetorium à de Abelterium. Esta última teria colocado sistematicamente miliários no seu território. A verdade, porém, é que não encontramos a mesma abundância a oriente de Alter do Chão. Mas, a confirmarem-se tantos miliários, talvez a estrada, pelo menos entre Ponte de Sor e a ribeira de Seda, tivesse todas as milhas assinaladas por marcos.

Frei Bernardo de Brito, em Monarchia Lusitana, parte II, Livro IV, cap. XIIII, publicou um outro miliário que seria dedicado a Cómodo e Lúcio Vero e marcaria LXXXXVI milhas. O monge alcobacense teria encontrado a transcrição do texto do miliário em papéis de André de Resende e diz: "vi hũa pedra no caminho militar, que ha de Lisboa a Mérida, adiante da ponte de sor". Hübner publicou este miliário como falso em CIL II 437*. Félix Alves Pereira (1937: 61) tentou reabilitá-lo e Mário Saa (1956: 277), tomando-o por bom, supôs que deveria acharse 16 quilómetros adiante de Senhora dos Prazeres, para o lado de Alter.

A nomenclatura dos imperadores torna suspeito este miliário. É certo que André de Resende e Frei Bernardo de Brito poderiam ter copiado (ou restituído) mal um texto que, por apagado, seria de difícil leitura. Mas as LXXXXVI milhas acrescentam as nossas dúvidas. No 
tempo de Cómodo, não seria natural contarem-se as milhas a partir de Mérida até um ponto tão distante da capital da Lusitânia. A oriente de Ponte de Sor, as milhas contar-se-iam a partir da capital da civitas em que o lugar se encontraria - civitas que seria, como já veremos, a de Abelterium.

A estrada passava a ribeira de Seda sobre a ponte de Vila Formosa (PEREIRA, 1912), ainda hoje transitável, e dirigia-se a Alter do Chão, que parece dever identificar-se com a Abelterium do Itinerário de Antonino.

A identificação não pode dar-se por inteiramente provada e os achados arqueológicos feitos em Alter do Chão não permitem classificar o sítio com segurança: trata-se de cidade ou villa? O nome de Alter pode, porém, considerar-se como derivado de Abelterium (VASCONCELOS, 1911: 336; MACHADO, 1993).

Já anteriormente propusemos a classificação de Alter do Chão (= Abelterium) como capital de civitas (AlARCÃO, 1988, vol. I: 29). A distância a que Ebora Liberalitas Iulia (Évora) e Ammaia (S. Salvador de Aramenha) se encontram uma da outra dificilmente permite que se admita serem as duas civitates, contíguas. É possível que a área de Alter do Chão e Monforte corresponda a outra civitas. Que a de Évora não alcançava Monforte sugerem-no as inscrições funerárias IRCP, n. ${ }^{\text {os }} 578$ e 579a, consagradas a cidadãos inscritos na tribo Quirina. A primeira foi encontrada na herdade do Mateus (freguesia de Vaiamonte, concelho de Monforte) e a segunda, na freguesia de Monforte. Porque a tribo de Ebora Liberalitas Iulia era a Galéria, a área de Monforte já não pertenceria àquela cidade. É certo que a tribo de Ammaia era a Quirina (MANTAS, 2000: 409). Mas parece-nos que tornaríamos demasiadamente extenso o território de Ammaia se o fizéssemos vir até Monforte.

Os achados arqueológicos de Alter do Chão (FIGueIREDO, 1895: 316-317; OLEIRO, 1955-1956: 283-284; TiMóteO et alii, 1978: 279-280; ANTÓNIO e REIS, 2003) não são, porém, suficientes para classificarmos o sítio, com segurança, como cidade e muito menos, como capital de civitas. Mas não são mais expressivos os de Alter Pedroso, onde G. Arias (1987: 293) localiza Abelterium. Costa Veiga (1941: 31) sugeriu a localização de Abelterium no sopé e do lado norte do outeiro da Azinheira Alta, entre Alter do Chão e Alter Pedroso; mas baseou sua proposta apenas no cálculo das distâncias proporcionadas pelo Itinerário de Antonino e não em quaisquer vestígios arqueológicos significativos. 
De Alter do Chão partiriam duas vias: uma no sentido de Campo Maior; outra, no de Barbacena e Elvas. O primeiro traçado é o que a maioria dos autores considera que corresponde ao do Itinerário de Antonino. Vamos, pois, segui-lo antes de considerarmos o percurso de Alter do Chão a Elvas.

A estrada romana avançaria por Almarjão, Retaxo, Amoreira, Escravides, Monte do Mouro, Tapada do Alicerce, Soeira, Rabasca, Revelhos, Azeiteiros, Adens e Degolados (PEREIRA, 1937: 72 s.; VASCONCELOS, 1927-1929: 185-198).

Estes (e outros) lugares acham-se citados numa vistoria de 1911 que pretendeu restituir ao domínio público a Canada do Alicerce. A vistoria permite-nos traçar por este alinhamento uma antiga via, provavelmente romana. Alicerce era o nome dado à estrada. Canada era um caminho por onde os rebanhos podiam seguir livremente (RIBEIRO, 1995: 389). A Canada do Alicerce era uma faixa de 16,40 a $24,60 \mathrm{~m}$ de largura.

De algum ponto deste percurso arrancaria, para norte, uma estrada que serviria Ammaia. Segundo Mário Saa (1956: 271), o "alicerce" viria do Crato e passaria pelo outeiro da Cabeça, a 4 quilómetros a oeste da estação ferroviária de Portalegre.

O problema da ligação a Ammaia carece, todavia, de mais atento exame, que aqui não faremos para não nos desviarmos da rota de Mérida. Talvez uma estrada saísse directamente de Alter do Chão com destino a Chocanal (Crato), onde se situava o vicus Camalocum, referido na inscrição CIL II 170 (= IRCP, n. ${ }^{\circ}$ 609).

O percurso do "alicerce" passa a sul de Arronches. Corre perto da capela de Nossa Senhora do Carmo, onde António Dias de Deus, Henrique da Silva Louro e Abel Viana (1955: 574) observaram um troço de estrada romana e "um marco miliário cuja inscrição se encontra quase completamente apagada". Seguia por Degolados e Campo Maior.

A via romana iria depois (segundo a maioria dos autores) à ermida de Bótoa, "que conserva, aunque ligeramente alterado, el nombre antiguo de Budua, [e continuaría] hasta cerca de la casa de la Pesquera, en un trayecto de 10 kilómetros, y sigue visible otros 10 antes de Montijo, no faltando tampoco grandes vestigios en el resto hacía Mérida" (BLÁZQueZ e SÁnchez Albornoz, 1919: 6). E continuam os autores: "En cuanto a Plagiaria, tuvo que hallarse entre la casa de Sagrajas y la Pesquera, en sítio próximo al ferrocarril de Mérida a Badajoz". 
O mesmo percurso é adoptado por J.-G. Gorges e F. G. Rodríguez Martín (1999: 256-257), que situam Plagiaria na zona chamada «El Pesquero». A estrada passaria ligeiramente a norte de uma importante villa romana parcialmente escavada (RUBIO MuÑOZ, 1988).

Sem contestarmos a existência da via cujo traçado acabámos de definir entre Abelterium e Augusta Emerita, não podemos deixar de assinalar as dificuldades que se nos levantam perante um miliário de Campo Maior com indicação LIII milhas e consagrado, em 222-225 d. C., a Severo Alexandre (CARVALHO, 1988; ENCARNAÇÃO, 1989: 90-92).

Segundo o percurso indicado, medimos, entre Campo Maior e Mérida, cerca de 70 quilómetros, isto é, pouco mais de 47 milhas - e não as LIII do miliário. A distância de Campo Maior a Bótoa é de cerca de 14 quilómetros, isto é, pouco mais de 9 milhas. Ora, porque Budua, segundo o Itinerário de Antonino, se achava a 38 milhas de Mérida, em Campo Maior deviam cumprir-se $38+8=46$ milhas e não as LIII do miliário. Consideradas estas diferenças, deveríamos admitir, entre Campo Maior e Bótoa, um percurso diferente e mais longo do que o traçado na nossa carta.

Por outro lado, se em Campo Maior se cumpriam LIII milhas contadas a partir de Mérida, e se ad Septem Aras se encontrava a 50 milhas de Augusta Emerita (conforme indicação do Itinerário de Antonino), deveríamos situar aquela mansio a 3 milhas a oriente ou sudeste de Campo Maior, eventualmente nas imediações de Vale de Albuquerque de Baixo. Ora, se localizarmos aqui ad Septem Aras, acharemos apenas 6 milhas até à ermida de Bótoa - e não as XII milhas do roteiro entre $a d$ Septem Aras e Budua.

Assumindo que ad Septem Aras ficava no percurso que traçámos, e considerada a distância daquela mansio a Budua, a identificação de Budua com Bótoa obriga-nos a situar a primeira destas estações a cerca de 3 quilómetros a sudeste de Degolados. Se a posição de ad Septem Aras era esta, então o miliário de Campo Maior não estaria originalmente aí colocado, mas em Degolados, donde teria sido trazido para Campo Maior.

Se é fácil admitir que o miliário de Campo Maior tenha sido trazido de outro lugar, o seu transporte de Degolados para Campo Maior não pode ser considerado sem sérias reservas, atenta a distância entre as duas vilas. Por outro lado, nas imediações do lugar onde hipoteticamente acabámos de situar ad Septem Aras não conhecemos vestígios arqueológicos que possamos equacionar com a mansio. 
Se admitirmos, de acordo com uma indicação alternativa do Itinerário de Antonino, que a distância de Budua a Plagiaria era de XII e não de VIII MP, a distância de ad Septem Aras a Mérida seria de LIIII MP - e o miliário de Campo Maior marcando LIII MP, não estaria (ou estaria apenas ligeiramente) deslocado.

O nome de ad Septem Aras sugere estação viária nas imediações de um santuário. Tal como os nomes actuais de Sete Fontes, Sete Rios e Sete Moinhos não significam exactamente sete, mas muitas fontes, muitos rios ou ribeiros, muitos moinhos, "Sete Aras" seria lugar com muitos altares ou inscrições votivas, isto é, um santuário. Não se nos afigura muito provável que as arae fossem monumentos megalíticos, como já foi sugerido (PEREIRA, 1937: 59, nota 2).

Nas imediações de Degolados não se encontraram, até agora, vestígios, directos ou indirectos, de um santuário. Apenas na herdade da Defesinha, a cerca de 4 quilómetros a norte de Ouguela, no concelho de Campo Maior, se achou uma ara consagrada D(eae?) S(anctae?) (F. E., 8, 1984, n. ${ }^{\circ} 32$; ENCARNAÇÃO, 1986: 106). É pouco para sustentarmos a existência, aqui, de um santuário - ainda que não devamos minimizar a importância do achado, pois, como justamente escreveu José de Encarnação, "a identificação do teónimo por siglas significa apenas que, por o monumento se destinar ao habitual lugar de culto, se dispensava uma identificação completa".

Nesta discussão da possível localização de ad Septem Aras, não podemos esquecer o que Mário Saa (1959: 149) escreveu: "Degolados possue origem romana. Mostra incalculável quantidade de fragmentos de telharia, pedras de cantaria, moedas, estatuetas, letreiros e profusão de alicerces. Isto se evidenciou principalmente quando aí se fizeram recentes removimentos de terras, para canalizações de água e de esgotos". Infelizmente, o autor não precisa o teor dos letreiros que terão sido achados.

De Degolados a Alter do Chão, a distância, medida pelo nosso traçado, é de cerca de 53 quilómetros, equivalente a 35 ou 36 milhas, superior às XXXII do Itinerário. Mas se ad Septem Aras ficava em Degolados ou nas suas imediações, como explicar que, em Campo Maior, se contassem LIII milhas? Terá o miliário sido trazido de um lugar que ficava a 3 milhas a ocidente de Degolados? Ou o miliário marcava a distância a Mérida não na via que corria por Bótoa, mas numa outra que, de Campo Maior, passando por Retiro, ia a Badajoz e daí à capital da Lusitânia? Como adiante diremos, parece-nos que Badajoz era ponto de 
passagem de uma via romana que o Itinerário de Antonino omitiu. $\mathrm{Ou}$ talvez a não tenha omitido. Seria a estrada que, vinda de Évora, por Évora Monte, e Estremoz, passava por Elvas e Badajoz. Neste caso, o Itinerário de Antonino não teria omitido a estrada romana mas algumas estações dela. Retomando o problema da reconstituição das estações omissas na via por Salacia e Ebora, teremos de rever a hipótese atrás posta de esta via passar por ad Septem Aras?

Se o percurso traçado de Alter do Chão até Bótoa, por Degolados e Campo Maior, suscita alguns problemas, afigura-se-nos viável. A localização exacta de ad Septem Aras e de Matusaro permanece, todavia, duvidosa.

Temos de considerar, porém, a existência de um caminho alternativo de Abelterium (Alter do Chão) para Augusta Emerita.

Mário Saa (1956: 182-190 e 294) sugeriu a existência de uma via de Alter do Chão a Cabeço de Vide, Vaiamonte, Torre de Palma (que identificou com a Matusaro do Itinerário de Antonino), Algalé e Monte das Esquilas. Daqui derivou um percurso por Santa Eulália até Elvas e outro até Campo Maior (que corresponderia, na sua opinião, a ad Septem Aras).

A via de Alter do Chão a Monte das Esquilas parece-nos mais do que provável. Passaria ela por Cabeço de Vide. André Carneiro (2004: 92-94), recolhendo notícias sobre achados romanos em Cabeço de Vide, concluiu que só há "dados soltos e fragmentados, nada esclarecedores para descortinar uma ocupação que é neste momento mais presumida que realmente conhecida". André Carneiro admite, porém, a existência de uma via que traça por Quinta do Pião, proximidades do marco geodésico das Ferrarias, Tapada do Vaz, Cabeço de Vide, Quinta da Ponte (sobre a ribeira de Vide) ou Arrossiada. A estrada continuaria pelo Monte de Merouços (sobre a ribeira do Carrascal) e pelos montes de Laranjeira, Fidalgo, Caliços e Gacho e passaria a oeste da villa de Torre de Palma (CARnEIRo, 2004: 160-165).

No percurso traçado por André Carneiro, mas ainda no concelho de Alter do Chão, teriam sido achados dois miliários que estariam guardados em casa de um particular daquela vila mas que o autor não conseguiu ver (CARNEIRO, 2004: 162). A publicação destes miliários é desejável: se não contêm indicação miliária, apenas confirmarão um percurso; se a contêm, poderão ajudar a esclarecer se Abelterium foi, ou não, caput viarum. 
No Monte das Esquilas, "em terras da herdade da Fonte Branca", uma ara aos Lares Viales (SAA 1956: 194-195 e 291-295; ENCARNAÇÃo, 1986: 105-106 e 1995: 631-634; A. E., 1995: 720 a-b) deixa suspeitar da passagem da via. Mais do que isso: de uma mansio ou mutatio - pois o mais natural seria que se fizesse sacrifício àqueles lares quando se iniciasse, retomasse ou completasse viagem. A distância de Alter do Chão ao Monte das Esquilas, pelo percurso indicado, é de cerca de 35 ou 36 quilómetros, isto é, 24 milhas. Ora, porque o Itinerário de Antonino situa Matusaro a XXIIII milhas de Abelterium, não podemos deixar de perguntar-nos se a tão procurada e ainda não encontrada estação de Matusaro não corresponde, afinal, ao Monte das Esquilas.

Seguindo o percurso que vimos traçando, a localização, aqui, de Matusaro, parece-nos credível - e mais credível que aquelas que lhe assinalaram Mário Saa e F. Alves Pereira (1937: 60) - este último, numa área entre Alegrete (Portugal) e Codesera (Espanha). Como mais adiante, porém, veremos, a identificação de Matusaro com Monte das Esquilas esbarra com sérias dificuldades - pelo que deveremos abandonar a hipótese, sem prejuízo de fazermos do sítio uma mansio ou mutatio.

A ara do Monte das Esquilas contém numa das faces uma outra consagração aos Lares de uma família Popillia. O gentilício é conhecido também em Mérida e Brozas (Cáceres). Ficamos na dúvida se uma família Popillia era proprietária da suposta mansio ou mutatio ou se um Popillius, passando por ali, consagrou o monumento aos Lares Viales e aos da sua família.

Do Monte das Esquilas, segundo uma versão de Mário Saa (1956: 291-292), a via seguiria por Torre do Curvo, monte da Serra d'Ares, monte de Alcobaça e Terrugem.

A passagem por Torre do Curvo parece confirmada por um miliário de Maximino e Máximo, datado de 236-237 (IRCP, n. ${ }^{\circ}$ 664). Mas não podemos esquecer-nos de um outro, talvez de Caracala, achado na herdade de Campos (Barbacena) (IRCP, n. ${ }^{\circ}$ 662) e dos que André de Resende (1996: 175-176) declara ter visto na área de Barbacena, sem precisar o local. Hübner considerou falsos estes dois últimos, CIL II 435* e 436* (= IRCP, n. ${ }^{\text {os }} 663$ e 661). Mas não deveremos reabilitá-los?

No miliário CIL II 435* (= IRCP, n. ${ }^{\circ}$ 663), consagrado a Heliogábalo, ler-se-ia [...]ORA MP XXII. A restituição [EB]ORA, aliás proposta pelo próprio André de Resende, é inaceitável, quer porque a distância àquela cidade é bem maior, quer porque o território de Ebora 
Liberalitas Iulia não viria até às imediações de Barbacena. Ficaria esta área no território de Mérida (ou de uma praefectura de Mérida)? A ser assim, contada a distância a partir da capital da Lusitânia, nunca poderia ler-se MP XXII, mas talvez algo como LXXII. Mas [...]ORA não se compagina com Emerita nem com Abelterium - as duas cidades a partir das quais se poderiam contar as milhas do miliário de Heliogábalo.

Talvez André de Resende tenha visto, de facto, um miliário do qual terá dado errada leitura. O autor confessa que a inscrição "já se lê, porém, a custo".

Mesmo que, por prudência, se prescinda deste miliário de André de Resende, não podemos ignorar os da herdade ou monte de Alcobaça.

J. Leite de Vasconcelos (1914: 249) publicou um miliário de Diocleciano e Maximiano, com indicação da milha XXXXXXV, aparecido "na herdade de Alcobaça, freguesia da Terrugem, concelho de Elvas, perto da antiga estrada de Lisboa a Badajoz". Foi republicado por José d'Encarnação em IRCP, n. ${ }^{\circ} 670$.

Maria José Almeida (2000: 102), por não encontrar, na freguesia de Terrugem, herdade chamada de Alcobaça e por existir, na freguesia de Vila Fernando, um Monte do Alcobaça, supõe que o miliário foi achado neste último lugar. Não se nos afigura impossível que Leite de Vasconcelos tenha errado na indicação da freguesia, tanto mais que Terrugem e Vila Fernando são freguesias contíguas. Neste monte do Alcobaça da freguesia de Vila Fernando, concretamente, no microtopónimo Cabanas (que a carta 1: 25. 000 não regista), terá sido encontrado um miliário dedicado a um imperador da dinastia dos Severos, dos imperadores sírios ou mesmo da Tetrarquia (IRCP, n. ${ }^{\circ}$ 679), sem indicação miliária.

Reconhecemos a complexidade do problema, que carece de uma indagação específica. Terá havido, nos inícios do séc. XX, na freguesia de Terrugem, alguma herdade de Alcobaça que hoje já não exista (ou não exista com esse nome)? Terá havido, posteriormente à data em que Leite de Vasconcelos escreveu (1914), alguma alteração dos limites entre as freguesias de Terrugem e Vila Fernando? Se, em 1914, havia apenas esse monte do Alcobaça que fica na freguesia de Vila Fernando, o seu proprietário seria também dono (ou arrendatário) de alguma outra herdade na freguesia de Terrugem e viria daí a confusão de Leite de Vasconcelos?

Os topónimos Monte de Alcobaça, Horta de Alcobaça e Malhada de Alcobaça encontram-se também na freguesia de S. Vicente e Ven- 
tosa do concelho de Elvas, mas não parece que devamos localizar aqui o miliário.

As dúvidas sobre o local exacto onde se acharia o miliário com indicação das XXXXXXV milhas reflectem-se na localização de Montobriga, estação viária que o Itinerário de Antonino menciona na via por Tubucci e que ficaria a 64 milhas de Mérida. Assumindo que a estação de Montobriga ficava na mesma via em que estava colocado o miliário, este deveria achar-se a uma milha de Montobriga, para ocidente ou noroeste. A essa distância do Monte do Alcobaça não conhecemos sítio que possa identificar-se com Montobriga. O povoado romano conhecido mais próximo é o do Monte da Nora. Parece ter sido importante, ainda que, por enquanto, não dispunhamos senão de escassa notícia dele (Gonçalves, Posselt e Teichner, 1999).

Seja como for, a estrada que vimos seguindo desde Alter do Chão, passando pelo Monte do Alcobaça, iria ao Monte da Nora, onde entroncaria na via de Ebora a Augusta Emerita. Ambas fariam então percurso comum por Elvas até Badajoz. Daqui, o caminho até Mérida poderia seguir pela margem esquerda do Guadiana.

Se efectivamente existiu a via que propomos, devemos perguntar-nos: é esta, afinal, a que o Itinerário de Antonino traça por Matusaro, ad Septem Aras e Budua? Nesse caso, onde ficariam estas duas últimas estações?

A identificação de ad Septem Aras é, como acabámos de ver, duvidosa. Tem sido objecto de múltiplas propostas, mas carecemos ainda de uma que seja convincente.

No séc. XVI, André de Resende (1996: 101-102 e 177-178) hesitou entre Alegrete e Assumar. Costa Veiga (1941: 30-31) propôs Degolados. Mário Saa (1956: 134 e 182) sugeriu Campo Maior ou Horta dos Surdos, a 3 ou 4 quilómetros a norte ou nordeste de Campo Maior e a 5 a sudoeste de Ouguela (SAA, 1967: 41 e 97). Félix Alves Pereira (1937: 59) e J. L. Melena (1984: 254) propuseram as imediações de Albuquerque. G. Arias (1987: 295) localizou a estação nas imediações de Campo Maior. Nós mesmos (AlARCÃo, 1999: 73) sugerimos a margem esquerda do rio Caia, algures a sudoeste de Campo Maior. No presente artigo, admitimos a possibilidade de ad Septem Aras ficar nas imediações de Degolados.

A passagem de uma via por Elvas é mais do que provável. André de Resende (1996: 176) diz que "em Elvas, em casa de certo fidalgo, estão por terra duas colunas para ali levadas da estrada, mas com as 
letras tão deterioradas que dificilmente em cada linha são visíveis duas ou três. Além disto nada mais vi desta estrada".

Ora, na herdade da Fonte Branca, a curta distância de Elvas, para oriente, foram encontradas duas aras a Prosérpina (IRCP, n. ${ }^{\text {os }} 573$ e 574).

As inscrições a Prosérpina IRCP, n.os 570, 571 e 572 são conhecidas através de Resende (1996: 204). Diz o autor, a propósito de Vila Viçosa: "Existiu aí, nos arredores, onde actualmente se encontra a igreja de Santiago, um santuário de Prosérpina. Encontrei lá estes monumentos, onde está escrito..." Os monumentos são os três citados do IRCP.

Apesar do que diz André de Resende, as três aras em causa têm sido republicadas como procedentes de ignoto lugar do aro de Elvas. Não procederão da herdade da Fonte Branca? Não haveria aqui um santuário a Prosérpina, junto do qual ficaria a mansio ad Septem Aras?

Tendo André de Resende visitado Elvas, não deixaremos de estranhar que não diga nada sobre o suposto templo da Fonte Branca (se tal templo existiu) nem sobre as inscrições romanas eventualmente descobertas nesse sítio. Já não seria visível o templo? Não se conheceriam, no séc. XVI, nenhumas inscrições procedentes do local? O sítio chamar-se-ia, em 1553, Torrejão. Num manuscrito de Victorino d'Almeida, existente na Biblioteca Municipal de Elvas, lê-se a propósito de Fonte Branca: "Atalaia de que resta uma só face... Foi provavelmente destruída pelos espanhóis na guerra da aclamação" (informações que devemos a Maria José de Almeida).

A hipótese de um templo a Prosérpina na Fonte Branca carece, pois, de confirmação. O nome Torrejão é sugestivo de algum edifício de certo vulto que aí subsistiria em 1553 - ou do qual, já desaparecido nessa data, podia haver memória.

Os achados epigráficos de Elvas são suficientes para nos fazerem crer que a cidade assenta sobre um aglomerado urbano que teve considerável importância na época romana. Devemos localizar ad Septem Aras mesmo em Elvas?

Procede de Elvas uma ara consagrada Dee Sancte Burrulobrigensi (IRCP, n. ${ }^{\circ}$ 566). O nome Dea Sancta podia aplicar-se a Atégina ou Prosérpina, deusas que, aliás, terão sido identificadas uma com outra (OLIvares Pedreño, 2002: 247-249; Garcia-Bellido, 2001). A Dea Sancta dos Burrulobrigenses era, provavelmente, Prosérpina. E Burrulobriga seria o nome de Elvas? 
Vasco Mantas (1998: 51) sugeriu a identificação de Burrulobriga com Borba, argumentando com a proximidade desta vila a Elvas e a afinidade linguística dos topónimos Burrulobriga e Borba. Não nos parece que tal afinidade exista e julgamos muito difícil sustentar a evolução de Burrulobriga para Borba. Quanto a este último topónimo, J. P. Machado (1993) considera-o de origem controversa mas admite a sua relacionação com vocábulo "céltico" que significaria "nascente" ou "limo". Em acréscimo, se Burrulobriga fosse o nome de Borba, como se explicaria o achado da ara em Elvas?

Será que Burrulobriga era o nome de Elvas e que a via para Mérida, passando por aí, não tinha sua mansio mesmo no oppidum, mas junto de um santuário de Prosérpina que ficaria logo adiante?

J. P. Machado (1993) considera de origem obscura o topónimo Elvas, do qual, no séc. XIII, temos as atestações Eluas e Eluis. Hübner (em CIL II 143) relacionou o topónimo com o gentilício Helvius. Parecendo credível, a derivação do topónimo a partir de Helvius, Helvii ou Helvia não deixa de suscitar dúvidas. Por outro lado, não se nos afigura inviável que uma Burrulobriga romana tenha mudado de nome em época tardo-romana ou posterior.

Se ad Septem Aras ficava ligeiramente a oriente de Elvas, as XII milhas do Itinerário de Antonino até Budua levam-nos, não a Bótoa, mas a Badajoz. Com efeito, a distância de Elvas a Bótoa excede largamente as 12 milhas romanas; mas esta é a distância de Elvas (ou da herdade da Fonte Branca) a Badajoz.

A identificação de Budua com Bótoa é tão consensual que só com muitas dúvidas e receios nos atrevemos a considerar a hipótese da sua localização em Badajoz, hipótese que todavia já foi sustentada no séc. XVI, por Dosma (citado por DíAZ EsteBAn, 1996: 16). Mas, regressando ao miliário de Campo Maior com indicação de LIII milhas, repetiremos que essa é sensivelmente a distância de Campo Maior a Mérida por um hipotético percurso passando por Retiro (na fronteira luso-espanhola) e Badajoz.

A cidade de Badajoz foi fundada por Ibn Marwān nos finais do séc. IX - mas o sítio não estava ermo (PICARD, 1981). Materiais do séc. IV ao I a. C. e romanos provam a ocupação do lugar na Idade do Ferro e na época romana. É certo que os materiais romanos são escassos e que se não reconheceram, até agora, estruturas de época romana (VALDÉS FERnÁNDEZ, 1988). Mas Budua seria um vicus ou simples mansio? 
Se não podemos demonstrar, pela positiva, a importância de Badajoz na época romana ou a sua condição de estação viária, também não podemos excluir tal hipótese - tanto mais que a eventual mansio (ou vicus?) poderia estar situada em área não coincidente com o centro histórico da actual cidade, onde se têm efectuado escavações.

A hipótese de ad Septem Aras ficar imediatamente a oriente de Elvas e de Budua coincidir com Badajoz esbarra, porém, com numerosas dificuldades.

A primeira reside na sobrevivência do nome Budua em Bótoa, sugerindo a localização da mansio no sítio que consensualmente lhe tem sido atribuído. É certo que a evolução Budua > Bótoa não deixa de suscitar algumas dúvidas. Com efeito, a evolução normal de Budua seria no sentido da manutenção do /d/ intervocálico ou no da sua perda. A passagem da sonora /d/ a surda /t/ não é corrente. Apesar de tudo, não podemos excluir a possibilidade (ou mesmo probabilidade) de uma evolução Budua > Bótoa. Mas não terá o nome de Budua/Bótoa mudado de lugar em época tardo-romana ou medieval? Será que o lugar de Badajoz, eventualmente chamado Budua na época romana, recebeu outro nome no tempo de Ibn Marwān e o antigo topónimo Budua foi aplicado a outro lugar? O caso do nome Conimbriga é um exemplo dessas transferências toponímicas. Perdido pela cidade antiga, transferiu-se para Aeminium, que passou a chamar-se Colimbria e depois, Coimbra. Aqui, porém, a migração do nome explica-se pela transferência da sede de bispado de Conimbriga para Aeminum, na época visigótica, tendo os bispos mantido o título de episcopi Conimbrigenses. Mas outro caso se pode dar como exemplo. O nome de Equabona, a primeira das estações viárias da estrada de Olisipo a Augusta Emerita por Salacia e Ebora, parece conservado no nome actual de Coina. Todavia, como vimos, é difícil sustentar a hipótese de a Equabona romana ter correspondido à Coina actual.

A povoação que Ibn Marwān fortificou e engrandeceu parece terse chamado, porém, Bataliu's ou Batalyaus, nome que os residentes pronunciariam Badagús (DíAZ EsTEBAN, 1996; PiCARD; 2000: 192). Se este nome corresponde à arabização de um romano ou pré-romano, não parece que Budua possa ter dado origem ao nome árabe.

Se a Budua do Itinerário de Antonino ficava em Bótoa, a distância dada por aquele roteiro não permite a identificação de ad Septem Aras com a herdade da Fonte Branca, a oriente de Elvas. 
Por outro lado, se na herdade do Alcobaça se contavam XXXXXXV milhas a partir de Mérida, ad Septem Aras - que fica a 50 milhas de Mérida - não podia achar-se na herdade da Fonte Branca, pois a distância entre as duas herdades é muito superior a 15 milhas.

Tudo ponderado, e sem prejuízo da existência de uma via de Abelterium a Augusta Emerita por Monte das Esquilas, herdade do Alcobaça, Monte da Nora, Elvas e Badajoz, parece-nos mais credível que ad Septem Aras ficasse nessa outra via que, de Alter do Chão, vinha por Campo Maior e Bótoa. A manutenção da hipótese de Matusaro em Monte das Esquilas e de ad Septem Aras na herdade da Fonte Branca exigiria a hipótese suplementar de uma estação intermediária que o Itinerário de Antonino teria omitido entre Matusaro e ad Septem Aras, visto que a distância entre o Monte das Esquilas e a herdade da Fonte Branca é muito superior às VIII milhas que o Itinerário de Antonino regista entre aquelas duas paragens. Se essa omissão é possível (há omissões na via por Salacia e Ebora, como vimos), não devemos pôr essa hipótese senão com a maior das reservas.

Mesmo que Budua se deva identificar com Bótoa e não com Badajoz, isso não contraria a hipótese da existência da estrada por Elvas e Badajoz.

Deste último lugar partiriam, para Mérida, duas estradas: uma, pela margem direita do Guadiana, passaria por Novelda del Guadiana, Valdelacalzada e Puebla de la Calzada; outra, pela margem esquerda do rio, iria por Talavera la Real e Lobón.

A estação de Plagiaria é identificada por alguns autores com El Pesquero (Gorges e RodríGuez Martín, 1999: 257). A distância que o Itinerário de Antonino assinala - a de XXX milhas a contar de Mérida - permite essa identificação.

A via da margem esquerda do Guadiana foi, como anteriormente dissemos, estabelecida por J.-G. Gorges e F. G. Rodríguez Martín (1999) a partir de um miliário encontrado na villa de Torre Águila (RoDRÍGUEZ MARTÍn, 1988 e 1999: 129). Os desvios do curso do rio explicam que se encontrem hoje na margem direita as ruínas de uma villa que, na época romana, se acharia na margem esquerda.

As estações ao longo da margem esquerda do Guadiana são numerosas (GoRGES, 1988), servidas por essa via que ia de Badajoz à capital da Lusitânia. 


\section{A Via de Olisipo a Augusta Emerita por Tubucci}

O percurso do Itinerário de Antonino é o seguinte:

Item alio itinere ab Olisipone

$\begin{array}{lll}\quad \text { Emeritam } & \text { CXXX } & \text { CCL } \\ \text { Ierabriga } & \text { XXX } & \\ \text { Scallabin } & \text { XXXII } & \\ \text { Tubucci } & \text { XXXII } & \\ \text { Fraxinum } & \text { XXXII } & \text { XXXIII } \\ \text { Montobriga } & \text { XXX } & \\ \text { Ad Septem Aras } & \text { XIIII } & \text { XXIIII, XL } \\ \text { Plagiaria } & \text { XX } & \\ \text { Emerita } & \text { XXX } & \end{array}$

Não temos outra referência a Tubucci para além da do Itinerário de Antonino. Ptolemeu II, 5, 6 menciona Tabucci ou Tacubis (consoante os manuscritos). Não é seguro que Tubucci, Tabucci e Tacubis se devam reduzir a um único e mesmo nome ou a uma mesma e única localidade.

Amílcar Guerra (1998: 614-615) aceita a identificação de Tabucci com Tacubis, considerando viável a metátese das consoantes, mas confessa a sua incapacidade de decidir sobre qual seria o nome original.

Francisco Villar (2000: 130), aceitando também que Tabucci e Tacubis correspondem a um mesmo lugar, considera arbitrário decidir qual a forma correcta do nome; acrescenta que a raiz * tab - não põe problema linguístico, mas que * tak - é praticamente inexistente na toponímia peninsular, na qual, todavia, existe $*$ tag .

Talvez Tacubis seja erro de copista e nunca tenha existido povoação com tal nome. Houve, sim, uma Tabucci ou Tubucci.

Tovar (1976: 268) identifica Tabucci com Tubucci. As duas formas encontram-se em diferentes manuscritos do Itinerário de Antonino, correspondendo, de modo óbvio, à mesma localidade. Se Konrad Miller optou por Tubucci, Kunz e Roldán Hervás preferiam Tabucci (ROLDAN HERVÁs, 1973: 66).

A identificação de Tubucci com Abrantes não tem fundamento (AlARCÃo, 2004 (2): 197-198). Também o não tem a identificação com Benavente, proposta por André de Resende (1996: 177) ou com Alvega, sustentada por Mário Saa (1956: 175) ou a localização de Tubucci nas imediações de Mora (ARIAS, 1987: 294). Continuamos a pensar que 
Tubucci pode ter ficado no vale do Sorraia (Alarcão; 1990: 367 e 2002: 45). Com efeito, o vale do Sorraia constitui um espaço geográfico que não nos parece integrável nem na civitas de Scallabis nem na de Salacia. Não ficaria aqui a civitas dos Turduli qui Bardili de Plínio 4, 118 ? O argumento de que o vale do Sorraia era de Lusitanos e não de Túrdulos (MANTAS, 2003: 54) não o julgamos convincente. O elemento -ip(p)o de Olisipo aponta para um horizonte étnico-linguístico túrdulo-turdetano e Ptolemeu designa como turdetanas as cidades de Salacia e Caetobriga. Os materiais recolhidos em Santarém, por outro lado, claramente documentam as afinidades da cidade com o mundo feníciopúnico ocidental. Com estas proximidades, não se nos afigura improvável a localização dos Turduli qui Bardili no vale do Sorraia. Por outro lado, a terminação - ucci aponta igualmente para um horizonte túrdulo-turdetano.

Tubucci podia ser a capital dessa civitas dos Turduli qui Bardili. No nosso Roman Portugal, poucas estações romanas identificámos no que poderá ter sido o território da civitas. Trabalhos recentes localizaram algumas mais (MANTAS, 2003, mapa de p. 56; QuARESMA e CALAIS, 2005). Vai-se assim compondo o quadro do povoamento do vale do Sorraia, na época romana.

Talvez a estrada, partindo de Scallabis e atravessando o Tejo, passasse por Almeirim, onde André de Resende viu um miliário incompleto (CIL II $4637=$ IRCP, $n .{ }^{\circ}$ 678). A passagem da via por Erra ou entre Santa Justa e Couço é mera suspeita. Ficaria Tubucci por aqui?

Não é mais seguro o percurso da via para oriente. Poderia correr por Mora, em cujas imediações G. Arias (1987: 294) localiza Tubucci, ou passar entre Casa Branca e Cano e nas imediações de Sousel, onde o mesmo autor supõe que ficaria Fraxinum. Em alternativa, a via romana podia correr por Pavia e a norte de Vimieiro e nas proximidades desta última povoação ficaria a mansio de Fraxinum. Corre por aqui uma ribeira do Freixo. Mas se "freixo" deriva de fraxinum, não podemos usar o hidrónimo como prova da localização da mansio, dado que são numerosos, no Alentejo, os pequenos cursos de água com o mesmo nome, justificado pela frequência com que freixos se desenvolvem nas margens de rios e ribeiros.

Numa outra hipótese, a estrada passaria sensivelmente a meia distância entre Casa Branca e Vimieiro e iria depois a Silveirona e Estremoz. Nesta última localidade recolheu-se um miliário que José d'Encarnação admite poder ter sido dedicado a Constantino (II), Flávio 
Valério Crispo e Valério Licínio Liciniano Júnior (IRCP, n. ${ }^{\circ}$ 675). A consagração não pode ser confirmada, dado o paradeiro hoje desconhecido do marco. Mas o autor chama justamente a atenção para o miliário de Flávio Júlio Crispo, Valério Liciniano Licínio Júnior e Flávio Cláudio Constantino encontrado na vizinha localidade de Silveirona (IRCP, n. ${ }^{\circ}$ 673). Por um poderemos reconstituir o outro.

De Estremoz, onde se encontraria com a via por Salacia e Ebora, a estrada iria por Borba (Evandriana?) ao Monte da Nora (Montobriga?), onde se encontraria com a que vinha de Abelterium.

A partir do Monte da Nora, as três estradas fariam percurso comum até Badajoz (Budua?) e, daí, até Mérida.

Devemos, todavia, admitir uma outra hipótese, dada a possível (ou provável) localização de Budua em Bótoa.

De Estremoz, a via de Tubucci subiria ao Monte das Esquilas, passando por Veiros. No Monte das Esquilas situar-se-ia, não a Matusaro de Itinerário de Antonino, mas a Montobriga do mesmo roteiro. Montobriga ficava, segundo o roteiro, a 64 milhas de Mérida. Na herdade do Alcobaça encontrou-se, como vimos, um miliário com indicação de XXXXXXV milhas. Mas a localização de Montobriga a uma milha da herdade do Alcobaça não é conclusão imperiosa, pois podemos admitir que Montobriga e a herdade do Alcobaça ficassem em estradas ou percursos diferentes.

Na hipótese de Monte das Esquilas corresponder a Montobriga, a via de Tubucci passaria por aqui e seguiria, por Santa Eulália, até às imediações de Degolados ou Campo Maior, onde ficaria ad Septem Aras.

A hipótese de ad Septem Aras nas imediações de Degolados tem contra ela, aparentemente, o miliário de Campo Maior com indicação de LIII milhas e a ausência de santuário romano nas imediações de Degolados. Quanto a este segundo ponto, temos de reconhecer, porém, que é mera hipótese a nossa sugestão de ad Septem Aras corresponder a mansio junto de santuário importante. Além disso, não podemos assegurar que não existiu santuário nas imediações de Degolados. Tudo quanto podemos dizer é que nunca foram descobertos ou noticiados vestígios arqueológicos ou epigráficos desse santuário.

Quanto ao miliário de Campo Maior, não é segura a sua posição original. Além disso, devemos pensar na possibilidade de acesso a Campo Maior por duas estradas vindas de Mérida: numa, por Badajoz e Retiro, contar-se-iam LIII milhas em Campo Maior; noutra, vinda por 
Bótoa e Alivã, contar-se-iam 47. O miliário conhecido reportar-se-ia à primeira via. Mas se, por outro caminho, a distância de Mérida a Campo Maior era de 47 milhas, contar-se-iam 50 (distância de Mérida a ad Septem Aras, segundo o Itinerário de Antonino) um pouco a sudeste de Degolados.

\section{Conclusão}

As propostas que apresentámos carecem de confirmação, quer através de aerofoto-interpretação, quer por batidas de campo. A primeira, aliás, não dispensa as segundas. A prospecção intensiva ou mesmo a escavação em alguns lugares que sugerimos como possíveis paragens das vias afigura-se-nos importante. $\mathrm{O}$ achado ocasional de miliários com indicação de milhas ajudaria a resolver muitos dos problemas. Infelizmente, parecendo relativamente abundantes (pelo menos em certos troços) os miliários anepígrafos (alguns dos quais poderiam ter inscrições pintadas), são poucos os epigrafados, e menos ainda os que contêm menção de milhas.

Esperamos que o nosso estudo estimule novas investigações. O que está em causa não é apenas o traçado das vias mas também a identificação de alguns lugares que podem ter sido povoados importantes na época romana.

\section{REFERÊNCIAS}

A. E. - L'Année Epigraphique

AlarCão, Jorge de (1988) - Roman Portugal, Warminster

AlarCão, Jorge de (1990) - Portugal, das origens à romanização (= Joel SERRÃo e H.

Oliveira Marques (dir.), Nova História de Portugal, vol. I), Lisboa

ALARCÃo, Jorge de (1999) - "Três notas sobre o Alentejo Romano", Al-madan, $2^{\mathrm{a}}$ série,

8: $72-74$

AlARCÃo, Jorge de (2001) - "A localização de Dipo e Evandriana", Al-madan, 2a série,

10: $39-42$

AlARCÃo, Jorge de (2002) - "Scallabis e o seu território", in Ana Margarida ARRUDA (coord.), De Scallabis a Santarém, Lisboa: 37-46

AlARCÃo, Jorge de (2004 (1) - "Notas de Arqueologia, Epigrafia e Toponímia - I", Revista Portuguesa de Arqueologia, 7 (1): 317-342 
AlarCão, Jorge de (2004 (2) - "Notas de Arqueologia, Epigrafia e Toponímia - II",

Revista Portuguesa de Arqueologia, 7 (2): 193-216

AlmeIDA, Maria José (2000) - Ocupação rural romana no actual concelho de Elvas

(Tese de mestrado, policopiada, apresentada à Faculdade de Letras de Coimbra)

ANTÓNIO, Jorge e REIS, Marta Pinto (2003) - "Intervenção arqueológica na necrópole

tardo-romana de Alter do Chão”, Al-madan, $2^{a}$ série, 12: 179-180

ARIAS, Gonzalo (1987) - Repertorio de caminos de la Hispania romana. Edição do autor Atlas antroponímico de la Lusitania romana, Mérida/Bordéus, 2003

AzEvedo, Pedro A. de (1987) - "Extractos archeologicos das «Memórias Parochiaes de

1758»," O Archeologo Português, 3: 225-244

BILOU, Francisco (2000) - "Testemunhos arqueológicos da via romana Ebora-Salacia no concelho de Montemor-o-Novo" Al-mansor, 14: 5-16

BILOU, Francisco (2005) - Sistema viário antigo na região de Évora, Lisboa

Blázquez, A. e SÁnchez-Albornoz, C. (1919) - "Vias romanas de Bótoa a Mérida...",

Memorias de la Junta Superior de Excavaciones y Antigüedades, 24

Bronseval, Claude de (1970) - Peregrinatio Hispanica (Introdução, tradução e notas de Dom Maur Cocheril), Paris

CARDOZO, Luís (1747-1752) - Diccionario Geographico, tomos I e II, Lisboa

CARNeIRo, André (2004) - Povoamento romano no actual concelho de Fronteira, Fronteira

Carvalho, Rogério (1988) - "Miliário de Severo Alexandre em Campo Maior", Ficheiro Epigráfico, 25, n. ${ }^{\circ} 115$

Deus, António Dias de; Louro, Henrique da Silva; Viana, Abel (1955) - “Apontamentos de estações romanas e visigóticas da região de Elvas (Portugal)", III Congreso Arqueologico Nacional (Galicia, 1953), Saragoça: 568-578

Díaz Esteban, Fernando (1996) - "Proemio. El nombre de Badajoz", in Bataliu's. El reino taifa de Badajoz. Estudios (ed. Fernando Díaz Esteban), Madrid, 1996: 11-19

EnCARnAÇÃo, José d' (1984) - Inscrições romanas do Conventus Pacensis. Subsídios para o estudo da romanização, Coimbra.

ENCARNAÇÃO, José d' (1986) - "Inscrições romanas do conventus Pacensis: aditamento", Trabalhos de Arqueologia do Sul, Évora, 1: 99-109

EnCARnAÇão, José d' (1989) - “A população romana de Campo Maior”, Trabalhos de Antropologia e Etnologia, 29 (1-4): 83-94

EnCARnAÇÃo, José d' (1995) - “A colecção epigráfica de Mário Saa no Ervedal”, Humanitas, 47: 629-645

F. E. = Ficheiro Epigráfico, Coimbra, Instituto de Arqueologia da Faculdade de Letras

FERnANDES, A. de Almeida (1999) - Toponímia portuguesa. Exame a um dicionário, Arouca

FerreIrA, Carlos Jorge et alii (1993) - O Património arqueológico do distrito de Setúbal. Subsídios para uma carta arqueológica, Setúbal

FERrEIRA, Fernando Bandeira (1959) - “Ab Olisipone Salaciam”, Revista da Faculdade de Letras, Lisboa, $3^{\mathrm{a}}$ série, 3: 168-195

FigueIREDO, A. Mesquita de (1895) - "Informações archeologicas colhidas no Diccionario Geographico de Cardoso”, O Archeologo Português, 1: 316-380 


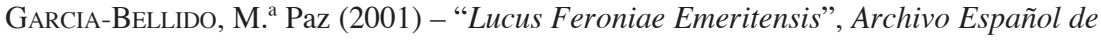
Arqueologia, 74: 53-71

Gonçalves, A.; Posselt, M.; Teichner, F. (1999) - "New aspects of the romanization of the Alto Alentejo (Portugal). Evidence from a geophysical and archaeological survey at the Monte da Nora (Terrugem)", Arqueologia (Porto), 24: 101-110 Gorges, J. - G. (1988) - "Prospections archéologiques autor d'Emerita Augusta", in Hommage à Robert Etienne (= Publications du Centre Pierre Paris, 17), Bordeus : 215-236

Gorges, J.-G. e Rodríguez Martín, F. G. (1999) - "Un nouveau milliaire de Magnence en Hispanie. La borne de Torre Águila (Montijo, Badajoz): épigraphie et territoire”, in Gorges, J.-G. e Rodríguez MARTín, F. G., Économie et territoire en Lusitanie romaine, Madrid : 241-262

GuERRA, Amílcar (1998) - Nomes pré-romanos de povos e lugares do Ocidente peninsular (Tese de doutoramento, policopiada, apresentada à Faculdade de Letras de Lisboa)

IRCP = José d'ENCARNAÇÃO, Inscrições romanas do conventus Pacensis, Coimbra, 1984

LiZARDO, João (2003) - “É urgente defender o sítio arqueológico de Água Branca e os vestígios romanos que lhe são associáveis”, Al-madan, 2a série, 12: 199-200

Machado, José Pedro (1993) - Dicionário onomástico etimológico da língua portuguesa, Lisboa

Mantas, Vasco Gil (1996) - A rede viária romana da faixa atlântica entre Lisboa e Braga (Tese de doutoramento, policopiada, apresentada à Faculdade de Letras de Coimbra)

Mantas, Vasco Gil (1998) - "Colonização e aculturação no Alentejo romano”, Arquivo de Beja, série III, 7-8: 33-61

Mantas, Vasco Gil (2000) - "A sociedade luso-romana do município de Ammaia”, in J.-G. Gorges e T. Nogales Basarrate (coords.), Sociedad y cultura en Lusitania romana. IV Mesa redonda internacional, Mérida: 391-420

Mantas, Vasco Gil (2003) - "Os romanos na região de Coruche", in Cristina CAlaIS (coord.), O homem e o trabalho. A magia da mão, Coruche: 53-69

MAnTAS, Vasco Gil (2004) - "Vias e portos na Lusitânia romana", in J.-G. Gorges e T. Nogales BASARRATE (coords.), V Mesa redonda internacional sobre Lusitania romana: las comunicaciones, Madrid: 427-453

MelenA, José L. (1984) - “Un ara votiva romana en El Gaitán”, Veleia, 1: 233-260 Oleiro, J. M. Bairrão (1955-1956) - “Archaeologica”, Humanitas, 7-8: 274-284

Olivares Pedreño, J. C. (2002) - Los dioses de la Hispania céltica, Madrid

Pereira, Félix Alves (1912) - "A ponte romana de Vila Formosa (Alter do Chão)", O Archeologo Português, 17: 209-222

PereIRA, Félix Alves (1937) - "Considerações sobre a interpretação do "Itinerarium" romano, na parte relativa às ligações viárias de "Olisipo" a "Emerita", capital da Lusitânia”, Memórias da Academia das Ciências de Lisboa, 2: 33-111

PICARD, Christophe (1981) - "La fondation de Badajoz par Abd al-Rahman Ibn Yunus al-Jilliki (fin IX" siècle)", Revue des Études Islamiques, 49 (2): 215-219 
PICARD, Christophe (2000) - Le Portugal musulman (VIIIe-XIII' siècle). L'occident d'al Andalus sous domination islamique, Paris

Quaresma, José Carlos e Calais, Cristina (2005) - "S. Pedro (Coruche): novos dados para o processo de romanização do Sorraia na época augustana e júlio-cláudia", Revista Portuguesa de Arqueologia, 8 (2): 429-447

RESENDE, André de (1996) - As Antiguidades da Lusitânia (Introdução, tradução e comentário de R. M. Rosado Fernandes), Lisboa

Ribeiro, Orlando (1995) - Opúsculos Geográficos VI. Estudos Regionais, Lisboa RodríGuez Martín, Francisco Germán (1988) - "La villa romana de la Dehesa de Torre Águila en Barbaño-Montijo (Badajoz)”, Extremadura Arqueológica, 1: 201-219

RodríGueZ MarTín, Francisco Germán (1999) - "Los asentamientos rurales romanos y su posible distribución en la cuenca média del Guadiana", in J.-G. GorgES e F. G. RodríGUEZ MarTín, Économie et territoire en Lusitanie romaine, Madrid. 121-134

RoldÁn HeRvés, J. M. (1973) - Itineraria Hispana. Fuentes antiguas para el estudio de las vias romanas en la Península Ibérica, Valladolid/Granada

Rubio MuÑoz, L. A. (1988) - "Excavaciones en la villa romana de "Pesquero" (Pueblonuevo del Guadiana, Badajoz). Campañas de 1983 y 1984", Extremadura Arqueológica, 1: 187-200

SAA, Mário (1956) - As grandes vias da Lusitânia, I, Lisboa

SAA, Mário (1959) - As grandes vias da Lusitânia, II, Lisboa

SAA, Mário (1963) - As grandes vias da Lusitânia, IV, Lisboa

SAA, Mário (1967) - As grandes vias da Lusitânia, VI, Lisboa

SChUlten, A. (1937) - Fontes Hispaniae Antiquae, IV, Barcelona

Silva, Carlos Tavares da e SoARES, Joaquina (1986) - Arqueologia da Arrábida, Lisboa

Silva, J. Candeias (1989) - "Miliário de Constantino Magno", Ficheiro Epigráfico, 33, n. ${ }^{\circ} 152$

Silva; J. Candeias; Batista, Álvaro; GasPar, Filomena (2003) - "Miliário de Constantino Magno de Vale da Lama (Bemposta, Abrantes)", Ficheiro Epigráfico, 72-73, n. $^{\circ} 319$

Silva, J. Candeias; Batista, Álvaro; GaSPAR, Filomena (n. p.) - Carta arqueológica do concelho de Abrantes, no prelo

SiLva, José Rafael Correia da (1988) - Levantamento arqueológico do concelho de Ponte de Sor (Trabalho apresentado ao Instituto de Arqueologia da Faculdade de Letras de Coimbra)

SiLVA, José Rafael Correia da e EnCARnAÇÃo, José d" (1990) - "Uma placa monumental de Ponte de Sor", Ficheiro Epigráfico, 36, n. ${ }^{\circ} 162$

SOARES, Joaquina (2000) - "Arqueologia urbana em Setúbal: problemas e contribuições", in Actas do Encontro sobre Arqueologia da Arrábida, Lisboa: 101-130

Tiмóteo, Maria Fernanda et alii (1978) - "Arqueologia romana do concelho de Alter do Chão (Subsídios para o seu estudo)", Actas das IIIas Jornadas Arqueológicas, Lisboa, Associação dos Arqueólogos Portugueses: 273-292 
Tovar, António (1976) - Iberische LandesKunde. Zweiter Teil. Die Wölker und die

Städte des antiken Hispanien. Band 2. Lusitanien, Baden-Baden

VALDÉs FERnÁNDEZ, F. (1988) - "La alcazaba de Badajoz”, Extremadura Arqueológica, 1: 263-277

VASCONCELos, J. Leite de (1905) - Religiões da Lusitânia, II, Lisboa

Vasconcelos, J. Leite de (1911) - Lições de Philologia Portuguesa, Lisboa

VASCONCELOS, J. Leite de (1914) - "Marcos miliários do Museu Etnológico Português",

O Archeologo Português, 19: 249-251

VAsConcelos, J. Leite de (1927-1928) - "Antiguidades do Alentejo", O Archeologo

Português, 28: 158 - 200

Veiga, A. B. Costa (1941) - " A via romana de Lisboa-Alter-Mérida”, Trabalhos da Associação dos Arqueólogos Portugueses, 5: 15-36

VILLAR, Francisco (2000) - Indoeuropeos y no Indoeuropeos en la Hispania prerromana, Salamanca

Wesseling, P. (1735) - Vetera Romanorum Itineraria sive Antonini Augusti Itinerarium, Amesterdão

\section{INVENTÁRIO DOS MILIÁRIOS}

\section{Via de Olisipo a Augusta Emerita por Salacia e Ebora}

1. Porto da Lama, Santiago, Alcácer do Sal

IRCP, n. ${ }^{\circ} 671$ e p. 758 , nota 1

Cronologia: Diocleciano, Maximiano, Constâncio Cloro e Galério (293-305 d. C.)

D(ominorum) N(ostrorum) DIOCLE/[TIA]NI ET MAX[I]/[MIA]NI SE[M]/P[ER] AVG(ustorum) ET C[ONS]/[TANT]I(i) ET M[AX]/[IMIN?]I FO[RTISSI]/ [MO]RVM IN[VIC]/[TO]RVM ET [MA?]/XIMINI

[FOR]/[TISS]IMORV[M]/[CAES]ARVM

2. Santa Susana, Alcácer do Sal

CIL II 434*

Cronologia: Caracala (213 d. C?)

IMP(erator) CAES(ar) DIVI / SEP[TIMII] SEVERI PII / ARAB(ici) ADIA$\mathrm{B}$ (enici) PARTHI/CI MAX(imi) BRIT(annici) [M]AX(imi) F(ilius) / DIVI $\mathrm{M}($ arci) ANTON(ini) PII GERM(anici) SARM(atici) NEP(os) / DIVI ANTON(ini) PII PRONEP(os) / DIVI HADR[IANI] ABNEP(os) / DIVI TRAIANI PARTHIC[I] / ET DIVI NERV[AE] ABNEP(os) / M(arcus) AVR(elius) ANTO$\mathrm{NIN}($ us $)$ / P(ius) F(elix) AVG(ustus) PAR(thicus) MAX(imus) / BRIT(annicus) MAX(imus) GERM(anicus) MAX(imus) / PATER(?) MILITVM TRIB(unicia) / POT(estate) XX IMP(erator) III CO $(n) \mathrm{S}($ ul $)$ III / P(ater) $\mathrm{P}($ atriae $) \mathrm{PROC}($ onsul $)$ $\operatorname{REST}($ ituit $)$ 
3. Tabuleiros, Evora

CIL II 433*

Cronologia: Maximiano (286-305 d. C)

IMP(eratori) CAES(ari) / MAXI/MIANO / PIO FELI/CI AVG(usto) [EB]ORA MP / XII

4. Évora Monte

IRCP, n. ${ }^{\circ} 674$

Cronologia: Flávio Júlio Valério Licínio Júnior e Flávio Cláudio Constantino (320 d. C.)

[D(ominis) N(ostris) FLAVIO IVL]IO / [VALE]RIO LICINIO IVN(iori) / [ET?] FLAVIO CLAVDIO / [CONSTA]NTINO CONSVL(i) / NOB(ilissimis) CAES(aribus)

Via de Olisipo a Augusta Emerita por Aritium Praetorium

5. Junto do rio Alpiarça

CIL II 439*

Cronologia: Trajano (98 d. C)

IMP(erator) CAES(ar) [DIVI] / [NERVAE] [F(ilius)] [NERVA]/TRAIANVS AVG(ustus) / GER(manicus) PONT(ifex) MAX(imus) / TRIB(unicia)

POTEST [AT] / IS (sic) II RESTITV / IT / X / I

6. Junto do rio Alpiarça

Resende, De Ant. Lus., fol. 162 (= RESENDE, 1996: 178)

Cronologia: Caio Júlio Vero Maximino e Caio Júlio Vero Máximo (235-238 d. C.)

IMP / CAES CAIVS / IVLIVS VER[...] / NOB IMPERA/TOR V TRIBVNI/CIA PO/TEST. COS. PRO. P / PATRIAE [...]/[...]

A leitura de André de Resende é certamente incompleta e o texto deste miliário poderia ser idêntico ao do marco que o mesmo humanista registou, mais adiante, nas Mestas (hic, n. ${ }^{\circ} 13$ ) ou ao de Torre do Curvo (hic, n. $\left.{ }^{\circ} 19\right)$

7. Junto do rio Alpiarça

CIL II 4635 = IRCP, n. $^{\circ} 665$

Cronologia: Tácito (275 d. C.)

IMP(eratori) / CAESARI / M(arco ) / CLAVDIO / TACITO / PIO F(elici) IN/ VICTO / AVG(usto) PONTIF(ici) / M(aximo) TRIB(unicia) / POTESTA/TIS(sic) II $\mathrm{CO}(n) \mathrm{S}($ uli $) / \mathrm{P}($ atri $) \mathrm{P}($ atriae $)$ 
8. Junto do rio Alpiarça

CIL II $4636=$ IRCP, . $^{\circ} 666$

Cronologia: Tácito (275 d. C.)

IMP(eratori) / CAESARI / CLAVDI/O TACITO / PIO F(elici) IN/VICTO AVG(usto) / PONT(ifici) M(aximo) / TRIB(unicia) PO/TESTATIS(sic) II / $\mathrm{CO}(n) \mathrm{S}(u l i) \mathrm{PRO} /[\mathrm{CO}(n) \mathrm{S}(u l i)][\ldots]$

9. Junto do rio Alpiarça

CIL II 4637

Cronologia: Caracala (213-214 d. C.) (?)

[...] / [...] / [...] COS / IIII PROCOS / REFECIT

10. Junto do rio Alpiarça

CIL II 4634 = IRCP, p. 719

Tácito ?

[...]/RESTITV/TOR VRBIS (por ORBIS ?)

11. Pocariça, Bemposta, Abrantes

ENCARNAÇão, 1995: 642-643

Cronologia: Constantino, César (306 d. C.)

$\mathrm{D}$ (omino) N(ostro) / FLA(vio) VAL(erio) CONS/TANTINO NOB/ILISIMO(sic) CAES(ari) / AC FORTISIMO $($ sic $) /[$...]

12. Entre Vale de Lama e Aranhas de Baixo, Bemposta, Abrantes

F. E., 72-73, 2003, n. ${ }^{\circ} 319$

Cronologia: Constantino, César (306 d. C.)

$[\mathrm{D}($ omino $)] \mathrm{N}($ ostro $) /[\mathrm{FLA}($ vio $)] \mathrm{VAL}($ erio $) /[\mathrm{C}] \mathrm{O}(n) \mathrm{ST}[\mathrm{A}] /[\mathrm{N}] \mathrm{TIN} /$

[O] [N]OBI[L]/[ISSI]MO [AC FOR]/TISSIM/O CAESA/RE DIVI / CONST(ant)I PII FI/LIO

13. Encruzilhada das Mestas

CIL II 441*

Cronologia: Caio Júlio Vero Maximino e Caio Júlio Vero Máximo(236-238 d. C.)

IMP(erator) CAE(sar) CAIVS IVLIVS / VERVS MAXIMINVS PIVS FE/LIX INVICTVS AVG(ustus) PONT(ifex) / MAX(imus) PATER PATRIAE TRI/ BVNICIAE POTESTATIS (sic) TER. / CO $(n) \mathrm{S}(u l)$ / GERMANICVS MAX(imus) DACICVS / MAX(imus) SARMATICVS MAX(imus) ET / C(aius) IVLIVS VERVS MAXIMVS / NOBILISSI( $m u s$ ) CAESAR PRINCEPS / IVVENTVTIS GERMANICVS MAX(imus) / DACICVS MAX(imus) SARMATICVS MA$\mathrm{X}($ imus $)$ / IMP(eratoris) CAES(aris) CAI(i) IVLI(i) VERI MAXI/MINI PII FEL(icis) AVG(usti) GERMANIC(i) / MAX(imi) DACICI MAX(imi) SARMATI(ci) / MAX(imi) FORTISSIMI CAESA/RIS FILIVS IIII 
14. Crucifixo, Tramagal, Abrantes

A publicar por Joaquim Candeias da Silva em Ficheiro Epigráfico

Cronologia: Constantino, César (306 d. C.)

[...] / [CONS]TA/NTII / FILIO

15. Ponte de Sor

IRCP, n. ${ }^{\circ} 668$

Cronologia: Probo (276-282 d. C.)

$\operatorname{IMP}($ eratori $) \mathrm{CAE}[\mathrm{SA}] / \mathrm{R}($ i) $\mathrm{M}($ arco $) \mathrm{AVR}($ elio $) / \mathrm{PROBO} \mathrm{P}($ io $) \mathrm{F}($ elici $)$ /

INVICTO / [A]V[G](usto) P(ontifici) $\mathrm{M}($ aximo $) /[\ldots]$

16. Adiante de Ponte de Sor

CIL II 437*; Brito, Mon. Lus., II, liv. IV, cap. XIIII

Cronologia: Caracala

L. COMMODO VERO / ANTONINO P. F. AVG. / GERMANICO

DACICO /PARTHICO ADIABEN. / IMP. IIII COS. III PROC. P. P. /

M. AVRELIO / ANTONINO PIO FELI / AVG. GERMANICO DACI/CO ADIAB. PART. MAX./IMP. VI COS. VIII P. P. / AB EMERITA / M.P. LXXXXVI

17. Nossa Senhora dos Prazeres, Alter do Chão

IRCP, n. ${ }^{\circ} 666$ a

Cronologia: Tácito (275 d. C.)

IMP(eratori) / CAES(ari) / MARCO / CLAVDIO / TACITO / PIO FELICI / INVICTO / AVG(usto) $\mathrm{P}($ atri ?) $\mathrm{P}($ atriae ?) / II CO(n) S(uli) [...]

18. Campo Maior

F. E. , 1988, n. ${ }^{\circ} 115$

Cronologia: Severo Alexandre (222-225 d. C.)

IMP(erator) CAES(ar) / M(arcus) [AURELIVS] SEVERVS / [ALEXANDER] PIVS FELIX [AVG(ustus)] / PONTIFEX MAXIMVS / TRIB(unicia) POTES(tate) $\mathrm{P}($ ater $) \mathrm{P}($ atriae $) \mathrm{CO}(n) \mathrm{S}(u l)$ / PROCONSVL FECIT / LIII

\section{Via de Abelterium a Augusta Emerita por Elvas}

19. Torre do Curvo, Monforte

IRCP, n. ${ }^{\circ} 664$

Cronologia: Maximino e Máximo (235-238 d.C.)

IMP(erator) CAES(ar) / G(aius) IVL(ius) VERVS MAXIMINVS / PIVS FELIX AVG(ustus) PONT(ifex) MAX(imus)/P(ater) P(atriae) TRIB(unicia) POTES(tate) 
III CO(n)S(ul) / GERM(anicus) MAX(imus) DAC(icus) MAX(imus) SARM(aticus) MAX(imus) / G(aius) IVL(ius) VERVS MAXIMVS NOBILISSIMVS CAES(ar) / PRINCEPS IVVENTVTIS GERM(anicus) MAX(imus) / DACI(cus) $\mathrm{M}[\mathrm{AX}($ imus $)] / \mathrm{IMP}($ erator?) $[\ldots]$

20. Herdade de Campos, Barbacena, Elvas

IPCP, n. $^{\circ} 662$

Caracala, 211-217 d. C.

[IMP(erator) CAES(ar)] [...] / M(arcus) [AVRELIVS] / SEVERVS PIVS / FELIX AVG(ustus) / PONT(ifex) MAXIMVS / [...]

21. Área de Barbacena

CIL II 436* = IRCP, n. ${ }^{\circ} 661$

Cronologia: Caracala (198-217 d. C.)

IMP(eratori) CAES(ari) DIV[I] [SEVE]/RI PII FIL(io) [...]

22. Área de Barbacena

CIL II $435^{*}=$ IRCP, n. ${ }^{\circ} 663$

Cronologia: Heliogábalo (219 d. C.)

IMP(eratori) CAES(ari) DIVI ANTONI/NI PII MAGNI FIL(io) / DIVI SEPTIMI SEVERI / PII NEPOTI M(arco) AVRE/LIO ANTONINO / P(io) FEL(ici) AVG(usto) PONT(ifici) MAX(imo) / TRIB(unicia) POT(estate) II CO(n)S(uli) II / PROC(onsuli) P(atri) P(atriae) / FORTISSIMO FELICISSI/MOQUE PRINCIPI / [EB]ORA M(ilia) P(assuum $)$ / XXII

23. Herdade de Alcobaça, Vila Fernando, Elvas

IRCP, n. ${ }^{\circ} 670$

Cronologia: Diocleciano e Maximiano (286-305 d. C.)

$\mathrm{D}$ (ominis) N(ostris) IMP(eratoribus) / DIOC/LETI/ANO E/T MAXS/IMIAN/O $\mathrm{MP} / \mathrm{XXXXXX/V}$

24. Herdade de Alcobaça, Vila Fernando, Elvas

IRCP, n. ${ }^{\circ} 679$

Cronologia: ?

$\mathrm{IMP}($ eratori $) / \mathrm{C}($ aesari $) \mathrm{MA} / \mathrm{RCO} \mathrm{A} / \mathrm{VR}($ elio $)$ AV/G M[...]/[...]

Via de Olisipo a Augusta Emerita por Tubucci

25. Silveirona, Estremoz

IRCP, n. ${ }^{\circ} 673$

Cronologia: Crispo, Licínio-o-Jovem e Constantino (II) (317 d. C. ?) 
D(ominis) N(ostris) / FLAVIO IVLI/O CRISPO/ VALERIO LICI/NIANO LICI/ NIO IVNI/ORI E[T) [F]LA/VIO CLAV/DIO CO(n)STA/NTINO NO/BI(lissimi)S CAES(aribus)

26. Estremoz

IRCP, n. ${ }^{\circ} 675$

Cronologia: Constantino II e Valério Licínio Liciano Júnior?

D(ominis) N(ostris) CONSTANT[INO] / [VALERIO LICINIANO NOBIL(issimis)] CAESAR(ibus) [...]

\section{Miliários de Integração Duvidosa}

27. Área de Vila Viçosa?

IRCP, n. ${ }^{\circ} 676$

Cronologia: Constante (333-337 d. C. ?)

FLAVI $<$ V $>$ S / VALERIVS / CONSTANS / CAESAR/[...]

28. Área de Elvas?

CIL II 4629

Cronologia: Trajano?

\section{$[\ldots] /[\ldots]$ NERVAE F / GER MX / [...]IV[...] / [...] XXIIII}

Este texto foi reproduzido, por Hübner, de um manuscrito de Cenáculo. Assumindo que este registou inscrições sobretudo nas áreas de Beja e Évora, Hübner considerou tratar-se de marco achado na área de uma ou outra das referidas cidades. Mesmo admitindo que o número faltante na indicação miliária era apenas $\mathrm{X}$, a distância de [X]XXIIII parece-nos demasiada para podermos considerar Ebora ou Pax Iulia como ponto de origem da contagem das milhas. Talvez apenas na via de Pax Iulia a Fines se pudesse alcançar número tão elevado de milhas. O mais provável, porém, é que neste miliário se contassem as milhas a partir de Augusta Emerita. Em tal caso, o miliário poderia estar na área de Elvas - quer na via que vinha de Estremoz, quer na que procedia de Alter do Chão. Menos provável nos parece a sua localização na via de Campo Maior - mas apenas porque não encontramos, nos manuscritos de Cenáculo, registo de outras inscrições da área campomaiorense. 


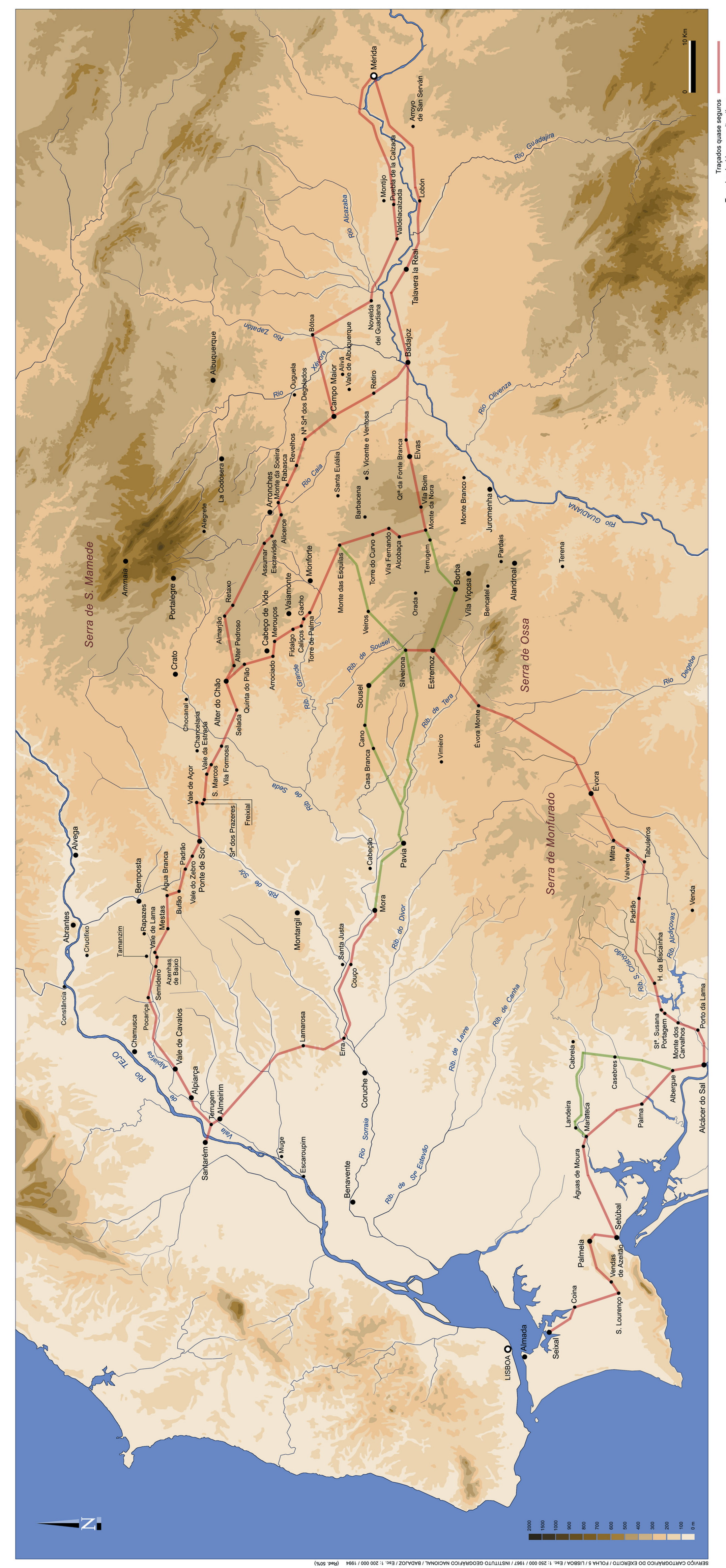

